Review

\title{
Current Perspectives on HIV-1 Antiretroviral Drug Resistance
}

\author{
Pinar Iyidogan and Karen S. Anderson* \\ Department of Pharmacology, School of Medicine, Yale University, New Haven, CT 06520, USA; \\ E-Mail: pinar.iyidogan@yale.edu
}

* Author to whom correspondence should be addressed; E-Mail: karen.anderson@ yale.edu; Tel.: +1-203-785-4526; Fax: +1-203-785-7670.

External Editor: Eric O. Freed

Received: 28 July 2014; in revised form: 8 October 2014 / Accepted: 20 October 2014 /

Published: 24 October 2014

\begin{abstract}
Current advancements in antiretroviral therapy (ART) have turned HIV-1 infection into a chronic and manageable disease. However, treatment is only effective until HIV-1 develops resistance against the administered drugs. The most recent antiretroviral drugs have become superior at delaying the evolution of acquired drug resistance. In this review, the viral fitness and its correlation to HIV-1 mutation rates and drug resistance are discussed while emphasizing the concept of lethal mutagenesis as an alternative therapy. The development of resistance to the different classes of approved drugs and the importance of monitoring antiretroviral drug resistance are also summarized briefly.
\end{abstract}

Keywords: HIV-1; antiviral therapy; drug resistance; evolution; lethal mutagenesis; resistance monitoring

\section{Introduction}

HIV-1 belongs to the retrovirus family and the etiologic agent of the acquired immunodeficiency syndrome (AIDS) that targets the human immune system [1]. In 2012, an estimated 35.3 million people lived with HIV while 1.6 million AIDS-related deaths occurred worldwide [2]. Currently, there is no cure for HIV infection. However, more than two decades of extensive scientific research has led to discovery of 26 FDA approved antiviral drugs with different mechanisms of action $[3,4]$. Nowadays, three or four drugs are combined as a multi-drug regimen, also known as highly active 
antiretroviral therapy (HAART). Most of the combination therapies include two nucleoside reverse transcriptase inhibitors (NRTIs) and one non-nucleoside reverse transcriptase inhibitor (NNRTI) or protease inhibitor (PI). Also, combinations of integrase or entry inhibitors with RT inhibitors and PIs are used as an alternative treatment strategy. Even though the current anti-HIV drugs and treatment strategies keep the viral load suppressed and the patients relatively healthy, the development of HIV drug resistance reduces or even eliminates the efficacy of antiretroviral treatment. HIV-1 possesses a high mutation rate and a high frequency of recombination, which could result in rapid emergence of drug-resistant variants when the viral replication is not sufficiently inhibited [5,6]. In this review, we will mainly focus on several topics to cover different aspects of HIV drug resistance: (i) the role of viral fitness in the treatment of HIV infection and evolution of resistance; (ii) lethal mutagenesis. Finally, we will also briefly discuss (iii) the currently available treatment options and (iv) the acquired drug resistance mutations during antiretroviral therapy as well as (v) the importance of clinical monitoring for drug resistance.

\section{Viral Fitness and Its Influence on Drug Resistance}

HIV-1 is a member of the retrovirus family having a high rate of mutation. Estimates of HIV mutation rate depend upon a number of factors including size of viral population and viral fitness of mutant strains. Earlier studies to measure the HIV mutation rate in vivo have determined a forward mutation rate of $3 \times 10^{-5}$ mutations per target base pair per replication cycle [7]. A recent study highlights important caveats in experimental design for determining and comparing estimates of viral mutation rates [8]. Studies of HIV from clinical patient isolates suggest rapid viral turnover $\left(10^{8}\right.$ to $10^{9}$ virions per day) [9-11], large numbers of infected cells $\left(10^{7}-10^{8}\right)$ [12], and a high level of recombination [13] The inherent high mutation rate by HIV generates a genetically diverse set of viruses usually from a single infecting viral genome [14]. The combinations of these genetically distinct HIV-1 subtypes exhibit different pathophysiological properties $[15,16]$. The viral "swarms" of heterogeneous populations are called quasispecies $[17,18]$. The quasispecies theory has linked the evolution trajectory of RNA viruses and viral pathology [19,20]. More insight into the theory revealed that the enhancement of viral mutagenesis above the error threshold could lead to error catastrophe [21-23] or extinction [24]. The high mutation rate of HIV-1 is crucial for adaptation to environmental changes like intracellular nucleotide concentrations, presence of mutagens, etc., that might affect the overall fidelity of the replication process [25,26]. More importantly, fidelity is vital for host cell infection efficiency and emergence of drug resistance [11,27]. In vitro measurements of HIV-1 reverse transcriptase (RT) fidelity indicate that de novo mutations are generated in the course of error-prone DNA synthesis while generating base substitutions, frame shifts, genetic rearrangements and hypermutations [28,29]. The main source for the high mutation rate of HIV-1 is due to the absence of 3' $\rightarrow$ 5' exonucleolytic proofreading activity of HIV-1 RT [30,31]. Several kinetic studies of recombinant RT indicated a high level of misincorporation during polymerization, suggesting the contribution of RT for the hypermutability of HIV-1 [32,33]. Additionally, the fidelity of HIV-1 RT during the two polymerization steps, the minus-strand DNA synthesis from an RNA-template and plus-strand DNA synthesis from a DNA-template, plays a major role in determining the rate at which mutations occur. Another source for the additional mutations in HIV-1 genome could derive from the 
host RNA polymerase II during the synthesis of the plus-strand viral RNA [34,35]. However, O'Neil et $a l$, suggested that the majority of the mutagenesis in the viral genome is a result of misincorporation by HIV-1 RT rather than the host cell RNA polymerase II [36].

An increased mutation rate ensures the adaptability of virus in a changing environment such as utilization of ART, but the fine tuning of hypermutability before losing the viral fitness is crucial for HIV. One mechanism to tune HIV-1's mutation rate is established through the interplay between the viral protein Vif (viral infectivity factor) and the host protein APOBEC3G, a cytosine deaminase [37-39]. The inhibitory effect of APOBEC3G in HIV-1 infection was first discovered in PBMCs that were infected with an HIV-1 strain lacking the Vif gene [40]. APOBEC3G has been shown to generate G-to-A hypermutations via deamination of cytosines to uracils during reverse transcription in newly synthesized minus-strand viral cDNA [41-44]. The presence of uracils in cDNA may then activate a cellular uracil-DNA glycolase causing the failure of reverse transcription. As a consequence, the proviral integration into the host genome is impaired in Vif-defective virus [42,45]. Additionally, the massive C-to-U conversion in the minus strand leads to ubiquitious G-to-A hypermutation of the proviral plus-strand cDNA after the integration of the proviral double stranded cDNA [46-48]. Thus, APOBEC3G is a critical element of an innate defense mechanism against HIV-1 infection. In essence, the host biologically induces lethal mutagenesis to defend itself against viral infections. HIV tackles the APOBEC3G-mediated hypermutagenesis with a counterattack. This involves binding of viral Vif protein to APOBEC3G and inducing polyubiquitination and degradation of APOBEC3G [49]. Recent advances in understanding this binding interaction between Vif and APOBEC3G [50] and the related mechanism of action studies will be important to develop novel antiviral drugs that targets the host and viral protein binding partners [51,52]. Moreover, a recent review presented how the mutation rate of HIV-1 could be modulated via the APOBEC3G-Vif interaction in order to adjust to the severe changes in environment and the evidence for the coevolution of both proteins through mathematical evolutionary modeling studies [53].

Besides the host-encoded enzymes altering the viral coding sequence and the error-prone retroviral replication process, genetic recombination is another process in the viral evolution of HIV-1 that contributes to viral fitness and avoidance of deleterious mutations while conserving the genomic information under the selective pressure such as antiviral drug treatment [54,55]. Mulder et al., showed that only the recombination of hypermutated HIV-1 with wild type (WT) virus generated replicationcompetent drug resistant viruses [56]. The recombination takes place primarily during minus-strand or rarely during plus-strand DNA synthesis and associated with a single crossover [57-59]. Earlier studies showed that RT switches templates between 2 to 13 times per genome replication and an average of three crossovers is detected per genome in the course of one cycle [55,59,60]. Additionally, the number of crossovers increases to an average of 9 and 30 per replication cycle for $\mathrm{T}$ lymphocytes and macrophages, respectively [61]. The recombination ability provides an efficient mechanism to redistribute mutations while elevating variation in the viral population. Generating multi-drug resistant variants in a viral population through the frequent recombination cycles hinders antiviral treatment [62-65]. As noted above, this characteristic escape route that HIV-1 exploits should be further investigated in the context of hypermutation. At this point, lethal mutagenesis could be an alternative strategy to fight against the multi-drug resistance problem through artificially increasing mutations 
with the use of chemical mutagens to a point that even the recombination-mediated repair of defective retroviral genomes would no longer function and eventually lead to error catastrophe.

\section{Lethal Mutagenesis}

The inherent infidelity of HIV-1 RT generates a wide diversity of mutated progeny and this property is crucial for viral evasion from the host immune defense or ART, and provides an extraordinary adaptability for the virus [66]. However, a high error rate of HIV-1 RT also leads to deleterious effects on the viral fitness after reaching a certain threshold. For instance, exploring the effects of mutations in the protein-coding regions of HIV-1 genome by sequencing revealed that all of the mutations were nonsynonymous and almost half of these were deleterious due to some premature stop codons [67]. Therefore, it has been proposed that the use of a mutagenic nucleotide analogue should slowly accumulate mutations over multiple rounds of replication, which then leads to elevated mutational load until the induction of lethal mutagenesis via generation of defective or non-infectious viral particles.

The concept of lethal mutagenesis introduced by Loeb et al., was first introduced to HIV-1 by using a mutagenic deoxynucleoside analogue, 5-hydroxy-2'-deoxycytidine (5-OH-dC) that reduces the fidelity of replication [68]. When the error threshold is approached with a mutagenic agent, small increases in mutation rates give rise to large declines in viability [69]. However, these mutagenic nucleosides need to be metabolically activated to their corresponding 5 '-triphosphate forms by cellular kinases in order to exhibit their mutagenic activities after the penetration of these nucleoside analogues (NA) into the infected cells via passive diffusion or the nucleoside transporters as highlighted in Figure 1 [70]. Interestingly, the initial phosphorylation step is considered to be the rate-limiting step compared to the subsequent phosphorylation steps catalyzed by deoxynucleoside mono- (dNMPK) and diphosphate kinases (dNDPK) to afford the active nucleoside analogue triphosphates (NA-TP) responsible for the mutagenic activity [71]. Subsequently, the pharmacologically active mutagenic nucleoside analogue triphosphate is incorporated into the nascent viral DNA strand by HIV-1 RT during minus-strand DNA synthesis, which would generate mispairs in the subsequent plus-strand DNA synthesis as shown in Figure 1. Consequently, incorporated mutagenic nucleosides lead to increased mutation rates. Similarly, the mutagenic ribonucleoside analogues are incorporated into viral RNA transcripts upon phosphorylation by cellular RNA polymerase II, resulting in base mispairing during subsequent RT-catalyzed minus-strand DNA synthesis in newly infected cells [72]. The removal of mismatched nucleotides is unlikely due to inefficient excision activity by the DNA repair enzymes from the RNA-DNA hybrid duplexes [73]. Therefore, mutations accumulate in the newly synthesized viral RNA genome per replication cycle and cause an irreversible genetic meltdown of the virus population until it reaches a point such that no functional viral proteins can be produced. Fortunately for the virus, the vast population size, genome structure and tight regulation of adaptive requirements have placed the virus populations very close to the extinction threshold. Hence, it has been suggested that altering the error frequency through a lethal mutagen could be ineffective for fully extinguishing the viral population or diminishing the spread of virus [24]. 


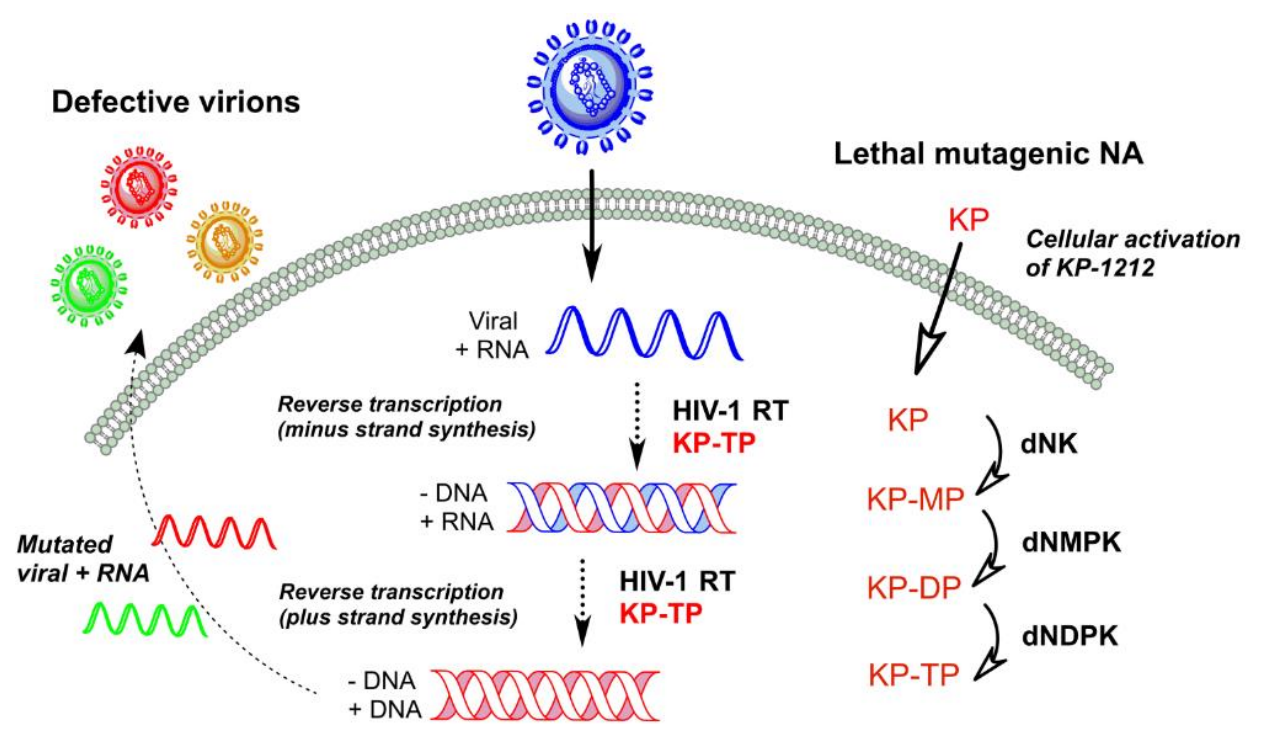

Figure 1. Schematic representation of HIV-1 lethal mutagenesis.

The early HIV-1 studies with $1 \mathrm{mM} 5-\mathrm{OH}-\mathrm{dC}$ resulted in irreversible loss of viral infectivity and by serial viral passage at round 17 no detectable levels of p24 were present [68]. On the contrary, no loss in viral titer was detected in the absence of the mutagenic analogue. 5-OH-dC shows its activity through presenting imino and amino tautomers [74] at physiological conditions and then base pairing with guanosine and adenosine. The sequence analyses of PCR products from the passage 16 virus indicated a 6-fold increase in the frequency of G-to-A transitions. The preferred adenosine over guanosine pairing of $5-\mathrm{OH}-\mathrm{dC}$ is a result of the imino tautomer frequency, which regulates the switched base pairing. The additional serial passage experiments with 5-OH-dC showed similar declines in viral titer and confirmed the G-to-A transitions [75]. Moreover, 5-OH-dC was non-toxic to the host genome since its incorporation was as low as one molecule per $1 \times 10^{5}$ nucleotides in cellular DNA and also no mitochondrial toxicity was detected [76]. The potential for utilizing ribonucleoside derivatives as mutagenic nucleoside analogues has been explored for 5-Azacytidine (5-AzaC) to induce HIV-1 lethal mutagenesis. 5-AzaC is clinically used to treat myelodysplastic syndrome [77] and has been also shown to inhibit HIV-1 replication in human CEM cells [78]. 5-AzaC could induce lethal mutagenesis through increasing the G-to-C transversions at drug concentrations that has no cell toxicity $[79,80]$. According to the proposed mechanism for 5-AzaC, ribonucleotide reductase converts 5-AzaC into its 2'-deoxyribonucleoside form that is subsequently phosphorylated and then the triphosphate form gets incorporated into viral DNA during reverse transcription by RT. Once incorporated into DNA, a water molecule attacks to the C6 position of the mutagenic nucleobase and cause ring opening while resulting in G-to-C transversions during the plus strand synthesis $[81,82]$. No significant adverse effects to the host cell were detected by 5 -AzaC, which could be due to the possible detection by the host DNA machinery and subsequent elimination from genomic DNA in case of incorporation [83].

KP1461 (N4-heptyloxycarbonyl-5,6-dihydro-5-aza-2'-deoxycytidine) is a prodrug of KP1212 (5-aza-5,6-dihydro-2'-deoxycytidine, Figure 2), which is another mutagenic deoxycytidine analogue that induces acceleration of HIV error rate during viral replication by RT [84]. KP1212 possesses ambiguous base pairing ability that elevates the number of random mutations in the viral genome. 
This drug tautomerizes between the amino and imino forms in the nucleobase moiety as shown in Figure 2, which could result in base pairing with guanine and adenine. Koronis Pharmaceuticals (Redmond, WA, USA) carried KP1461 into three Phase I and one Phase II clinical trials for the treatment of HIV. KP1461 is converted to KP1212 by liver enzymes and sequentially phosphorylated into its triphosphate form. Kinetic analysis of KP1212-TP incorporation by HIV-1 RT showed a 19- and 12-fold reduction in incorporation efficiency compared to the natural substrate (dCTP) for DNA and RNA templates, respectively [85]. The initial serial passage experiments of KP1212 reported an increase in the mutation and viral annihilation by passage 13 at $10 \mu \mathrm{M}$ [84]. The sequencing data from this study revealed a predominance of G-to-A and A-to-G transition mutations and to a lesser extent $\mathrm{C}$-to- $\mathrm{T}$ and $\mathrm{T}$-to- $\mathrm{C}$ transitions with no significant increase in transversions. These transitions are consistent with the coexistence of both tautomers as explained above. Most of the NAs cause mitochondrial toxicity during the long-term treatment [86]. Therefore, we have studied the potential mitochondrial toxicity of KP1212 by in vitro experiments [85]. Our results demonstrated that human mitochondrial DNA polymerase (Pol $\gamma$ ) could incorporate KP1212 into the DNA template as well as HIV-1 RT, which makes it potentially toxic to mitochondria. However, Pol $\gamma$ could efficiently excise the incorporated KP1212-5'-monophosphate (KP1212-MP) via its proofreading exonuclease activity. Moreover, mitochondrial toxic effects were also tested by a lactate assay in human CEM cells along with a test of mitochondrial DNA (mt DNA) synthesis after KP1212 treatment [84]. According to the results, only $6 \%$ decrease in mt DNA synthesis was detected with $320 \mu \mathrm{M}$ KP1212 and lactic acid quantities were insignificant up to $1 \mathrm{mM}$ of drug. The calculated $K_{\mathrm{i}}$ values of KP1212-TP for HIV-1 RT and Pol $\gamma$ were $95 \mu \mathrm{M}$ and $28 \mu \mathrm{M}$, respectively and the discrimination ratio between $\mathrm{dCTP}$ and KP1212-TP was 27 for Pol $\gamma$ and 78 for RT enzyme. Additionally, the incorporation efficiency of KP1212-MP with HIV-1 RT and Pol $\gamma$ is 11-fold and 26-fold lower than dCMP, respectively.

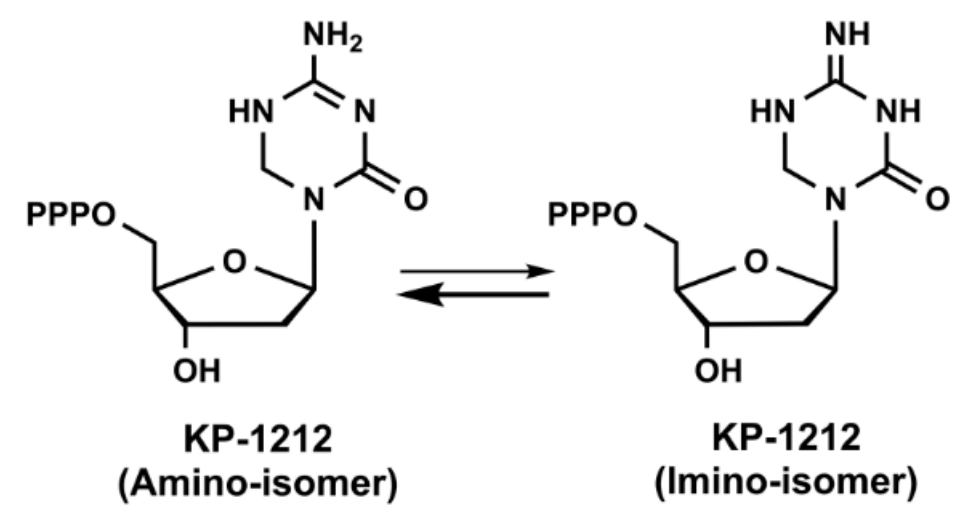

Figure 2. Chemical structures of KP-1212 in amino and imino isomer.

KP1461 successfully completed Phase Ia and Phase Ib human clinical trials with no serious toxicity concerns for healthy and HIV-infected subjects [87]. In the Phase I b study, HIV positive subjects demonstrated a statistically significant drop in viral load. After the encouraging results of Phase I study, KP1461 entered an open label Phase IIa clinical trial including chronically infected and treatment-experienced patients [88]. In this Phase IIa trial, salvage HIV patients received $1600 \mathrm{mg}$ of KP1461 as a monotherapy twice per day for 124 days. While these patients entered the trial with pre-existing drug resistance mutations, the analysis of clinical data exhibited no significant decrease in 
plasma viral load, and the number of resistance mutations was not increased by KP1461. Additionally, no new resistance mutations were selected during this short-term clinical study, yet the mutation spectrum was altered for HIV [89]. The sequenced viral genes originating from individual HIV-1 RNA templates revealed an excess of A-to-G and G-to-A transition mutations, and to a lesser extend T-to-C and C-to-T mutations compared to control group. It has been suggested that KP1461 could be coadministered with other inhibitors in addition to monotherapy, since the mutagen will further weaken the already poor viral fitness in failing ART regimens. In conclusion, KP1461 could offer a novel mechanism of action and invaluable advancement in the treatment of HIV-1 infection.

\section{Antiretroviral Drug Classes and Acquired HIV-1 Drug Resistance}

\subsection{FDA Approved NRTIs and Mechanisms of Resistance}

NRTIs play a central role in HAART and have been utilized extensively in the fight against HIV-1 infection [90]. NRTIs are administered as inactive prodrugs and require metabolic conversion to their corresponding active 5'-triphosphate forms by host cellular kinases [91]. These pharmacologically active drugs are efficiently incorporated into the viral DNA at the 3'-end as an NRTI monophosphate by HIV-1 RT while competing with the natural deoxynucleoside triphosphates (dNTPs). NRTIs bind at the nucleotide binding site as illustrated in Figure 3.Upon incorporation, these NAs inhibit the elongation of viral DNA chain due to the lack of a 3'-hydroxyl group or an altered sugar moiety that prevents the incorporation of next incoming nucleotide. The commonly used pyrimidine analogues are 2',3'dideoxy-2',3'-didehydrothymidine (d4T, stavudine) and 3'-azido-2',3'-dideoxythymidine (AZT, zidovudine) as thymidine (T) analogues, and 2'-deoxycytidine $(\mathrm{dC})$ analogues are $\beta$-1-(-)-2',3'-dideoxy3'-thiacytidine (3TC, Lamivudine), and $\beta$-1-(-)-2',3'-dideoxy-5-fluoro-3'-thiacytidine (FTC, emtricitabine). On the other hand, purine analogues are $\beta$-d-(+)-2',3'-dideoxyinosine (ddI, didanosine) as 2'-deoxyadenosine (dA) analogue, (-)-(1S,4R)-4-[2-amino-6-(cyclopropylamino)-9H-purin-9-yl]-2cyclopentene-1-methanol (ABC, abacavir) as 2'-deoxyguanosine ( $\mathrm{dG})$ analogue, and $R-9-(2-$ phosphonomethoxypropyl) adenine (TDF, tenofovir) as a chemically unique acyclic phosphonate nucleotide analogue. There are two main mechanisms underlying HIV-1 drug resistance towards NRTIs [91]. The first mechanism involves discriminatory mutations that would weaken the binding affinity of the NRTIs while retaining the binding efficiency of the corresponding natural dNTPs. As a result, the incorporation of NRTIs into the viral DNA diminishes and the virus continues to proliferate. The other common resistance mechanism is nucleotide excision representing the reversal of the polymerization reaction in order to restore the DNA synthesis. In this mechanism, RT utilizes ATP or inorganic pyrophosphate $\left(\mathrm{PP}_{\mathrm{i}}\right)$ as a co-substrate to remove the incorporated nucleoside analogue monophosphate (NA-MP) that terminates the DNA elongation [92,93]. 


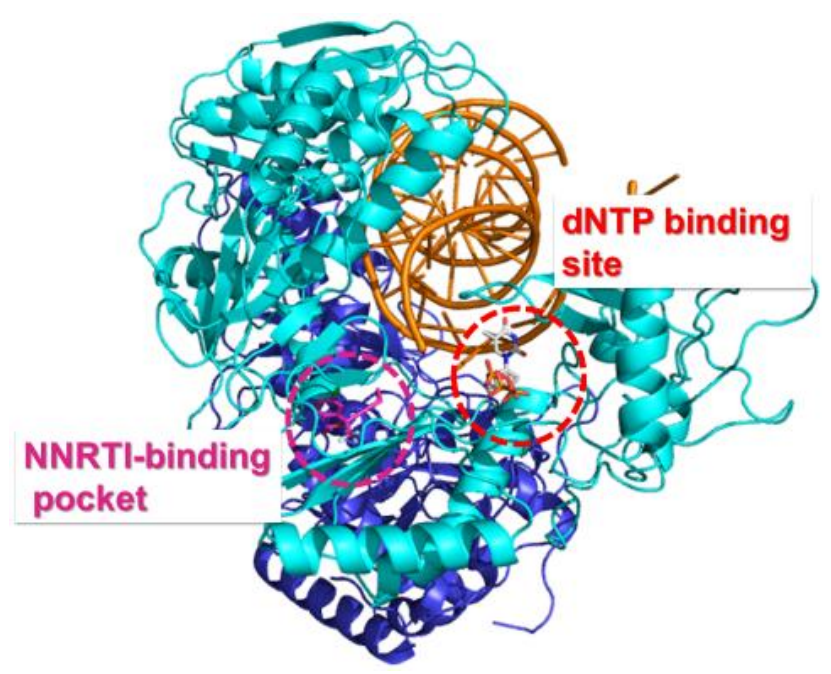

Figure 3. Overall view of the HIV-1 RT/DNA/dNTP ternary complex showing the corresponding binding sites of non-nucleoside reverse transcriptase inhibitor (NNRTI) (circled in magenta, efavirenz (EFV) is shown as magenta sticks) and NRTI (circled in red, dNTP is shown as sticks). The p66 and p51 subunits are represented in cyan and blue, respectively. PDB 1RTD [94].

\subsubsection{NRTI Specific Discriminatory Mutations}

The major NRTI mutations against the FDA approved drugs are listed in Table 1 and highlighted in Figure 4. The discrimination pathway is represented by K65R, L74V, Q151M, and M184V/I mutations, which diminish affinity of RT for specific NRTIs with no significant change in corresponding natural dNTP affinity. The amino acid K65 interacts with the $\gamma$-phosphate of the incoming dNTP [95] and K65R mutation mediates discrimination through reduced polymerization rate $\left(k_{\text {pol }}\right)$ for the incorporation of all NRTIs [96-98]. Viruses with the K65R mutation showed decreased susceptibility for TFV, 3TC, FTC, ddI, and ABC between 2- to 7.7-fold, but no significant resistance for AZT and d4T [99,100].

The side chain of M184 interacts with the ribose moiety and the nucleobase of the 3'-nucleotide in the primer, however substituting methionine with $\beta$-branched amino acids (valine, isoleucine, threonine) makes an interaction with the dNTP sugar moiety [95]. According to this structural information, binding of NRTIs with $\beta$ - or L- ring configurations like 3TC and FTC would be sterically hindered by M184V/I mutations [101,102]. These mutations are selected during 3TC and FTC treatment and confer a high level of resistance to them via interfering with binding of 3TC-TP and FTC-TP [103]. Additionally, M184V/I mutations decrease the viral replication capacity in the presence of low dNTP concentrations [104,105]. The clinical data has indicated that the prevalence of the M184V/I resistance mutation was significantly lower in patients who received FTC and TDF compared to those who received 3TC and TDF [106]. 
Table 1. Major NRTI Resistance Mutations.

\begin{tabular}{cccccccc}
\hline \multirow{2}{*}{ Consensus } & \multicolumn{7}{c}{ Amino acid mutations associated with } \\
\cline { 2 - 8 } & FTC & 3TC & TDF & ABC & ddI & d4T & AZT \\
\hline M41 & & & & & & L & L \\
K65 & R & R & R & R & R & R & L \\
D67 & & & & & & N & N \\
K70 & E & E & E & E & E & R & R \\
L74 & & & & V,I & V,I & & \\
Y115 & & & F & F & & & \\
M184 & V,I & V,I & & V,I & V,I & & \\
L210 & & & & & & W & W \\
T215 & & & & & & Y, F & Y, F \\
K219 & & & & & & Q,E & Q,E \\
\hline
\end{tabular}

The resistance mutations are compiled from the updated International Antiviral Society-USA (IAS-USA) and Stanford HIV drug databases. Mutations that are highlighted in bold represent the reduced susceptibility or virological response.

Q151 is located in the palm subdomain of the RT, where it contacts the 3'-OH of ribose moiety and the nitrogen base of the incoming dNTP [95]. The interaction with the 3'-OH group allows the Q151M mutant RT to better discriminate between natural dNTPs possessing 3'-OH, and NRTIs lacking this hydroxyl group [99]. Consequently, the Q151M mutation results in nucleotide discrimination through a reduction in the $k_{\text {pol }}$ values of NRTI incorporation [97,107,108]. Q151M and accompanying other mutations including A62V, V75I, F77L, and F116Y confer multi-NRTI resistance and this multiple mutational pattern is called Q151M complex. The Q151M complex viruses show high-level resistance to all NRTIs (>11-fold) except 3TC, FTC and TDF with minimal susceptibility changes around 2-fold $[99,100,109]$. Several other mutations around the $\beta 3-\beta 4$ hairpin loop, position 62 -to-72, have been associated with the Q151M complex. These mutations include T69N, K70G/Q or the deletion of T69 residue [110,111]. Residue K70 is located in the $\beta 3-\beta 4$ hairpin loop and K70E confers resistance to TDF by lowering its incorporation rate while preserving the binding affinity [98]. L74 interacts with the template strand at position +1 [112]. L74V mutation is selected by ddI and abacavir by reducing their $K_{\mathrm{i}}$ values $[99,113]$. In the presence of M184V, L74V confers reduced susceptibility to ABC and ddI [114] and appears to be associated with an inferior virologic response to TDF-based regimens [115]. 


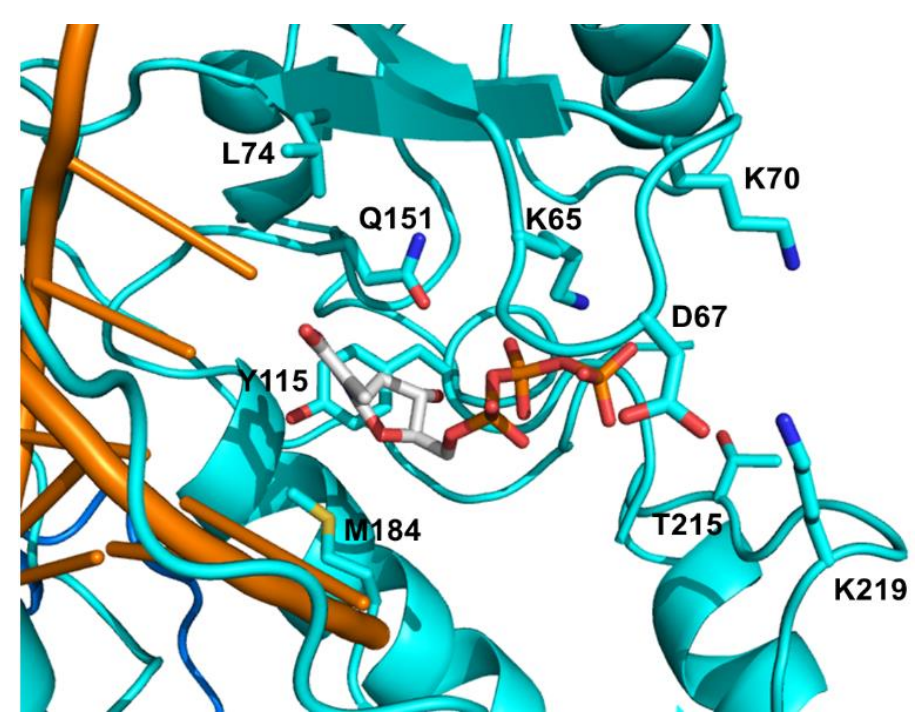

Figure 4. Detailed view of the NRTI binding pocket. The drug resistant mutation sites are shown in cyan sticks. dNTP is highlighted in sticks. PDB 1RTD [94].

\subsubsection{Excision of NRTIs}

Another common resistance mechanism observed in HIV-1 RT involves the selective removal of NRTIs from the 3 ' end of a chain-terminated viral DNA primer [116]. The removal of the chain terminator leaves the primer terminus compatible for further nucleotide incorporation again. In this excision mechanism, ATP and $\mathrm{PP}_{\mathrm{i}}$ nucleophilically attack the terminal phosphodiester bond of the chain-terminated primer, yielding a dinucleoside tetraphosphate [117] or nucleoside analogue triphosphate (NA-TP) [118], respectively. NRTI excision represents the reversal of the polymerization reaction in order to restore the DNA synthesis and it has been suggested that ATP is the physiologically relevant pyrophosphate donor for this reaction. Since AZT is the most efficiently removed NRTI among all NRTIs, excision of AZT has been extensively studied to explore the phosphorolytic removal mechanism [119]. Previous biochemical studies showed that a set of mutations including M41L, D67N, K70R, L210W, T215F/Y, and K219E/Q lead to high-level resistance to AZT and combinations of these mutations are designated as thymidine analogue resistance mutations (TAMs) or AZT resistance mutations (AZTr) [120,121]. Additionally, these mutations confer cross-resistance to AZT and $\mathrm{d} 4 \mathrm{~T}$, as well as to most NRTIs to varying degrees [122]. Boyer et al., suggested that some of the TAM mutations increase the AZT removal via enhancing the binding of ATP [123]. The excision of AZT5'-monophosphate (AZT-MP) from terminated primer by ATP results in the formation of AZT-5'tetraphospho-5'-adenosine (AZTp4A) as an excision product [124]. The excision reaction could be blocked by the next complementary dNTP, which forms a dead-end-complex (DEC) [125,126]. Once the dNTP occupies the nucleotide binding site (N-site) of the RT ternary complex, the chain terminator located at the end of a primer moves to the priming site (P-site), thus preventing the phosphorolytic excision of NRTIs and blocking the viral DNA synthesis [127]. TDF and d4T are the other commonly studied NRTIs for phosphorolytic excision reactions. While AZT-MP excision is highly dependent on TAMs, TDF removal is predominantly sensitive to DEC formation [128]. Moreover, we previously showed that ATP-mediated excision of TDF is more efficient using the polypurine tract (PPT) viral sequence than the primer binding site (PBS) sequence [129]. Introducing an NNRTI like EFV also 
forms a ternary complex resembling DEC and blocks the removal of TDF from the terminated primer. A recent crystal structure of AZTr mutant RT (M41L, D67N, K70R, T215Y, and K219Q) bound to both the AZTp4A and primer/template revealed that $\mathrm{T} 215 \mathrm{Y}$ and $\mathrm{K} 70 \mathrm{R}$ make specific binding interactions with AZTp4A and combinations of AZTr mutations form a high-affinity ATP binding site on the enzyme [130]. As a result, these mutations coordinate the excision product better than WT RT since none of these interactions are present in the WT structure [95]. Earlier studies demonstrated that dissociation of AZTp4A is the rate limiting step for continuing DNA synthesis [131] and the dinucleoside tetraphosphates like AZTp4A serve as substrates for RT and chain terminate the DNA elongation [132].

\subsubsection{Multi-NRTI Resistance Mutations}

Once RT acquires the TAM complex mutations with high resistance to thymidine analogues, it could also develop further mutations like T69 insertion complex and become resistance to variety of NRTIs [133]. HIV-1 RT variants with the insertion of dipeptides (Ser-Ser, Ser-Gly or Ser-Ala) near the residue T69 in the finger subdomain and several other mutations like M41L, A62V, T69S, K70R and T215Y decrease the viral susceptibility to AZT and d4T while enhancing the ATP-mediated excision activity of RT for both NRTIs [134]. Biochemical studies showed that the insertion mutations mostly destabilize the DEC formation with the terminated primer/templates including various NRTIs as chain terminators in the presence of physiological dNTP concentrations [135,136]. The other two main multi-NRTI resistance mutation groups including Q151 and TAM complexes are explained in the previous subsection. Patients treated with thymidine analogues develop two TAM pathways with high resistance to all NRTIs: TAM 1 (T215Y linked; M41L, L210W, and T215Y) and TAM 2 (T215F linked: D67N, K70R, K219E/Q, and T215F) [122]. Table 2 summarizes the multi-NRTI resistance mutations.

Table 2. Multidrug Resistance Mutations.

\begin{tabular}{cccc}
\hline \multirow{2}{*}{ Consensus } & \multicolumn{3}{c}{ Amino acid mutations associated with } \\
\cline { 2 - 4 } & 69 insertion complex & Q151 complex & TAMs \\
\hline M41 & L & V & L \\
A62 & V & & N \\
D67 & & & \\
T69 & Insert & R \\
K70 & R & I & \\
V75 & & L & \\
F77 & & Y & \\
F116 & & M & \\
Q151 & & & W \\
L210 & W & & Y,F \\
T215 & Y,F & & Q,E \\
K219 & Q,E & & \\
\hline
\end{tabular}

The resistance mutations are compiled from the updated International Antiviral Society-USA (IAS-USA) and Stanford HIV drug databases. 


\subsubsection{Investigational NRTIs and Emergence of Potential Resistance Mutations}

Two newly developed NRTIs showed improved safety and antiviral activity profiles with minimal drug resistance problems. The first drug is an adenosine analogue, 4'-ethynyl-2-fluoro-2'deoxyadenosine (EFdA), currently in Phase I clinical trials with superior activity profile compared to the approved NRTIs [137]. EFdA's antiviral activity is in the pM range against WT virus and more importantly, this new drug suppresses the replication of various multidrug-resistant HIV variants [138]. EFdA is unique in its structure and mechanism of action since EFdA-TP can be incorporated efficiently by its 3 '-OH group and block the translocation of the primer strand in the RT complex [139]. EFdA is not only potent against several multidrug-resistant variants such as K65R, L74V, M41L/T215Y, and Q151M complex [137,140], but also show favorable toxicity profiles and stability in plasma [141]. We also determined that the mitochondrial toxicity of this new analogue is neglible since EFdA-TP is a poor substrate for human mitochondrial DNA polymerase $\gamma$ [142]. Furthermore, our pre-steady-state kinetics studies showed that RT preferentially incorporates EFdA-TP over the natural dATP substrate and promoted delayed chain termination with unaffected fidelity [143]. In vitro resistance studies illustrated that novel combinations of mutations are selected by EFdA, in which the triple mutation, I142V/T165R/M184V, showed the highest resistance profile [137].

The next drug is a derivative of d4T, 2',3'-didehydro-3'-deoxy-4'-ethynylthymidine (Ed4T), in Phase IIb clinical trial. Unlike its predecessor d4T, Ed4T possess potent antiviral activity against viruses carrying K65R and Q151M resistance mutations and much less inhibitory effects on mitochondrial DNA synthesis [144,145]. More importantly, viruses with the entire Q151M complex mutations maintained susceptibility to Ed4T [146]. However, addition of M184V to this complex significantly decreased the susceptibility to this drug. Additionally, in vitro studies have demonstrated that M184V alone and P119S/T165A/M184V conferred 3- and 130-fold resistance to Ed4T, respectively [147]. Clinical isolates with T69 insertion complex including T210W and T215Y exhibited a high resistance to Ed4T [146].

\subsection{NNRTI Resistance}

Unlike NRTIs, NNRTIs possess diverse chemical composition and do not require intracellular activation to show their pharmacological activities [91]. Currently, there are five NNRTIs approved for treating HIV-1 infection: Nevirapine (NVP), Delavirdine (DLV), Efavirenz (EFV), Etravirine (TMC125, ETR), and Rilpivirine (TMC 278, RPV). NNRTIs bind to an allosteric hydrophobic site, approximately $10 \AA$ away from the polymerase active site, which is unique to HIV-1 RT and absent in host cell polymerases [148]. NNRTIs are non-competitive inhibitors since they do not interfere with dNTP binding, but rather induce conformational changes in the vicinity of the active site upon binding to the hydrophobic NNRTI-binding pocket (NBP), thus blocking the required alignment of substrates for the phosphodiester bond formation (Figure 5) [149-151]. 


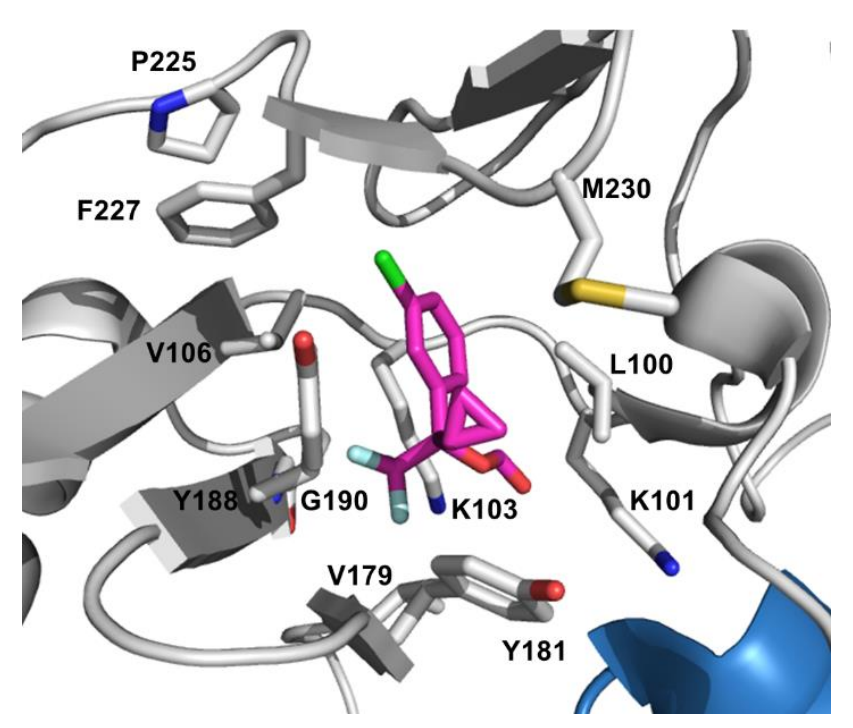

Figure 5. Detailed view of the NNRTI binding pocket. EFV is shown as magenta sticks and the EFV-resistant mutation sites are shown in white sticks. PDB 1FK9 [152].

NNRTIs have become a crucial part of HAART because of their minimal side effects and less toxicity profiles compare to NRTIs [153]. However, emergence of resistance and cross-resistance could diminish or completely abolish their therapeutic efficacy. There are several factors play an important role in NNRTI resistance such as the ease of sequence variability in residues aligning the NBP since no conserved sequence is required compare to the dNTP-binding site, and the effect of resistance mutations on drug susceptibility and viral fitness [154]. Table 3 summarizes the most common clinically significant NNRTI-resistance mutations. First-generation inhibitors including NVP [155], and DLV [156], have a lower genetic barrier to resistance than the second-generation inhibitors such as EFV [157]. Third generation compounds ETR [158] and RPV [159] have enhanced potency and effectiveness on drug-resistant mutants. Resistance mutations can emerge relatively quickly against the first-generation NNRTIs. Primary resistance mutations that are selected by these drugs are all located in the NBP, and reduce the binding affinity of the inhibitors or block their access to NBP [160]. This hydrophobic pocket is formed by amino acids L100, K101, K103, V106, T107, V108, V179, Y181, Y188, G190, F227, W229, L234, and Y318 of p66 and E138 of p51 [161,162]. 
Table 3. Major NNRTI Resistance Mutations.

\begin{tabular}{|c|c|c|c|c|}
\hline \multirow{2}{*}{ Consensus } & \multicolumn{4}{|c|}{ Amino acid mutations } \\
\hline & NVP & EFV & ETR & RPV \\
\hline V90 & & & I & \\
\hline A98 & & & $\mathrm{G}$ & \\
\hline L100 & I & I & $\mathbf{I}$ & $\mathbf{I}$ \\
\hline K101 & $\mathbf{P}, \mathrm{E}, \mathrm{H}$ & $\mathbf{P}, \mathrm{E}, \mathrm{H}$ & $\mathbf{P}, \mathrm{E}, \mathrm{H}$ & $\mathbf{P}, \mathrm{E}, \mathrm{H}$ \\
\hline K103 & $\mathbf{N}, \mathbf{S}$ & $\mathbf{N}, \mathbf{S}$ & & \\
\hline V106 & $\mathbf{A}, \mathbf{M}$ & M, A & I & \\
\hline V108 & I & & & \\
\hline E138 & & & $\mathrm{A}, \mathrm{G}, \mathrm{K}, \mathrm{Q}$ & $\mathbf{K}, \mathrm{A}, \mathrm{G}, \mathrm{Q}, \mathrm{R}$ \\
\hline V179 & $\mathrm{D}, \mathrm{E}, \mathrm{F}$ & $\mathrm{D}, \mathrm{E}, \mathrm{F}$ & $\mathrm{D}, \mathrm{F}, \mathrm{T}, \mathrm{E}$ & L,D,E,F \\
\hline Y181 & C,I,V & $\mathrm{C}$ & $\mathbf{C}, \mathbf{I}, \mathbf{V}$ & $\mathbf{C}, \mathbf{I}, \mathbf{V}$ \\
\hline Y188 & $\mathbf{C}, \mathbf{L}, \mathrm{H}$ & $\mathbf{L}, \mathbf{C}, \mathrm{H}$ & & $\mathbf{L}$ \\
\hline G190 & $\mathbf{A}, \mathbf{S}, \mathbf{E}, \mathbf{Q}$ & A,S,E,Q & $\mathrm{S}, \mathrm{A}, \mathrm{E}, \mathrm{Q}$ & A,S,E,Q \\
\hline H221 & & & & $\mathrm{Y}$ \\
\hline P225 & & $\mathrm{H}$ & & \\
\hline F227 & $\mathrm{L}, \mathrm{C}$ & $\mathrm{L}, \mathrm{C}$ & $\mathrm{C}$ & $\mathrm{C}$ \\
\hline M230 & $\mathbf{L}$ & $\mathbf{L}$ & $\mathrm{L}$ & $\mathrm{I}, \mathrm{L}$ \\
\hline
\end{tabular}

The resistance mutations are compiled from the updated International Antiviral Society-USA (IAS-USA) and Stanford HIV drug databases. Mutations that are highlighted in bold represent the reduced susceptibility or virological response.

\subsubsection{Resistance to First-generation NNRTIs}

DLV is precluded from clinical treatment due to its limited efficacy and inconvenient dosing requirements [163]. NVP is also no longer recommended as a part of first-line regimen NNRTI because of its toxicity profile and the availability of better options [164]. Currently, EFV is the only earliergeneration NNRTI that is used in combination therapies to treat HIV infection. The three most common single mutations that confer high-level resistance to all of the first-generation NNRTIs are K103N, Y181C and G190A and these mutations cause clinical failure [165].

The K103 position is located at the edge of the NBP and in the vicinity of the entrance to this pocket with its side chain pointing out. Structural data suggests that the K103N mutation forms a hydrogen bond to Y188 residue in the unliganded RT and this additional hydrogen bond keeps the entrance to the pocket closed, thus interfering with the ability of NNRTIs to enter the pocket $[166,167]$. These observations also explain the slow binding kinetic results of the inhibitors to K103N mutant enzyme [166]. The K103S mutation occurs less frequently in patients and causes resistance to DLV, NVP, and EFV [168]. Amino acid K101 also resides at the site of NNRTI entry part of the pocket and K101P mutation confers large reductions in susceptibility to all the currently approved NNRTIs [169].

NVP like inhibitors maintain a "butterfly-like" binding mode in the pocket and amino acids Y181 and Y188 stabilize the NVP binding through stacking interactions between their aromatic side chains and the pyridine groups on the inhibitor [170]. The crucial contribution of these aromatic ring stacking interactions to the NNRTI binding energy explains the drastic decrease in inhibitor binding once 
Y181C and Y188C mutations emerge [171]. Y181C causes 35-, 161-, and 3-fold reduced susceptibility to DLV, NVP, and EFV, respectively [172]. Even though the Y181C-mediated EFV resistance is at the low level, selection of the more resistant K103N mutation causes treatment failure with EFV [173]. This K103N/Y181C double mutant leads to cross-resistance to all NNRTIs in this group [174]. Y188L mutation exhibited cross-resistance to all the earlier-generation NNRTIs with high-level resistance to NVP and EFV [175].

The G190A mutation leads to high resistance to NVP and mid-level resistance to EFV through the steric hindrance between the alanine side chain and the bound NNRTI structure [172]. On the other hand G190A/S causes hyper susceptibility to DLV [176]. The less frequent G190E mutation confers high-level resistance to EFV and NVP while diminishing the polymerase activity simultaneously [177]. L100I is another steric hindrance mutation besides G190A and confers resistance to all NNRTIs [172].

\subsubsection{Resistance to Later-generation NNRTIs}

ETR and RPV are diarylpyrimidine (DAPY) derivatives and rationally developed using structurebased design approach in order to circumvent the inhibitory effects of the common NNRTI-resistance mutations [178]. Contrary to the earlier-generation NNRTIs with a low genetic barrier, second-generation NNRTIs possess an increased genetic barrier to the development of resistance due to their conformational flexibility in the NBP $[158,179]$. These next generation inhibitors adopts a horseshoe shape in the pocket, and maintain their binding interactions through reorienting or repositioning at the pocket even in the presence of the emerged mutations [180,181].

The crystal structure of ETR bound RT revealed an important hydrogen bond interaction between K101 and the central ring of the inhibitor [182]. Additionally, the benzonitrile group is positioned in a pocket formed by V106, P225, F227, L234, P236, and Y318 while aromatic side chains of Y188, F227, and W229 residues position towards the dimethylcyanophenyl group of ETR [180,182]. These structural data have also revealed no change in the binding mode of ETR in the presence of K103N mutation and actually N103 side chain makes van der Waals interactions with the inhibitor. This observation is also validated by the drug sensitivity assays resulting in sustained activity against the frequently observed double drug-resistant mutations, K103N/Y181C and K101E/K103N [158]. The resistance profile of ETR has been explored and L100I, V179F/I, Y181C, G190E, M230L, and Y318F mutations were identified from the ETR-resistant virus isolates $[179,183]$. Furthermore, these experiments indicated that high-level resistance to ETR could only be accomplished by accumulating at least two mutations such as Y181C/V179F, L100I/K103N/Y181C, and Y181C/K103N/V179I. Clinical studies have also shown that combinations of three or more mutations including V90I, A98G, L100I, K101E/H/P, V106I, E138A/K/G/Q, V179D/F/T, Y181C/I/V, G190A/S, and M230L reduce the virological response to ETR [165,184-187]. Among these mutation positions E138 and V179 are novel and specific to the later-generation NNRTIs conferring low-level resistance to ETR [188,189]. Moreover, emergence of E138K after Y181C mutation increases the ETR susceptibility compared to Y181C mutant alone [190]. Interestingly, several connection subdomain mutations, E399D and N348I, have been identified with diminished ETR susceptibility [191-193]. 
The resistance mechanism against RPV resembles ETR since their chemical structures with conformational flexibility and adaptability are similar [182]. Therefore, RPV has a high resistance barrier like ETR as well. Under the selective pressure from RPV, several mutations have emerged including V90I, L100I, K101E/P, V106A/I, V108I, E138A/G/K/Q/R/V, V179L/F/I, Y181C/I/V, Y188L, V189I, G190E, H221Y, F227C, and M230I/L [189,194]. In the previous subsection, we have specified that Y181C and the Y188 mutations cause resistance for the first-generation NNRTIs due to loss of the aromatic ring stacking interactions; such interaction losses would not affect the binding of later-generation NNRTIs [195]. A recent in vitro study demonstrates that addition of E138 mutations on top of Y181C mutation shows no significant enhancement in resistance to RPV or ETR [196]. Also, E138K is determined to be the most predominant mutation besides K101E for both RPV and ETR [196,197]. K101E confers high resistance to RPV and compensates for viral replication deficiency and enzyme processivity associated with M184I [197]. Additionally, E138A/G/K/Q/R mutations alone have modest resistance profile against RPV, however when combined with M184I it significantly decreases susceptibility to RPV and ETR [189]. Earlier biochemical studies suggested that E138K substitution alters the RPV dissociation and association equilibrium, thus reduce RPV susceptibility [198]. The same study also showed that M184I has decreased catalytic efficiency because of a decreased binding affinity of dNTP to the mutant RT. According to the ECHO and THRIVE clinical trials, virological failure was seen most frequently in the presence of E138K and M184I double mutant upon RPV treatment combined with emtricitabine/tenofovir [199]. In a different note, it has been shown that N348I connection domain mutation alone or along with the M184V mutation could prevent or delay the emergence of E138K in patients under RPV selection pressure and decrease the replication capacity of E138K virus via reducing the catalytic efficiency and RNase H activity of RT [193].

\subsection{Resistance to HIV-1 Protease Inhibitors}

HIV-1 protease is a viral aspartic protease that cleaves Gag and Gag-Pol polyproteins into individual functional proteins necessary for viral maturation [200]. Currently, there are nine FDAapproved protease inhibitors (PIs) for the treatment of HIV infection: Atazanavir (ATV), Darunavir (DRV), Fosamprenavir (FPV), Indinavir (IDV), Lopinavir (LPV), Nelfinavir (NFV), Saquinavir (SQV), Tipranavir (TPV), and Ritonavir (RTV). These inhibitors have been rationally designed with the aid of structure-based drug design and synthesized according to the substrate transition model [201]. All approved PIs are peptidomimetics excluding TPV and bind to the active site of the protease as competitive inhibitors (Figure 6) [202,203]. Additionally, RTV is only used as a boosting agent partner (only NFV could be used without the boosting agent RTV) due to its various side effects [204]. RTV is a potent inhibitor of cytochrome P450 3A4 (CYP3A4), thus increases the plasma concentrations of the partner protease inhibitors that are degraded in vivo by CYP3A4 [205].

PIs are essential in HAART regimens. However, development of drug resistance is an important hindrance for the success of protease inhibitor therapy [206]. HIV confers resistance by accumulating mutations within the enzyme that leads to reduced binding affinity of the inhibitors while maintaining the natural substrate binding interactions (Table 4). The HIV-1 protease is a homodimer consisting of 99 amino acid monomers [207]. Each monomer contributes to substrate binding, where the residues 
25-32, 47-53, 76 and 80-84 form the substrate binding pocket. The majority of the drug-acquired mutations arise at the active site pocket as well as the surrounding residues since the PIs have similar binding modes compare to substrates. Common primary resistance mutations include D30N, V32I, L33F, M46I/L, I47A/V, G48V, I50L/V, V82A/F/T/S/L, I84V, and L90M [208,209]. While some of these mutations are selected by a specific PI such as the D30N substitution occurrence during the NFV therapy [210], I84V mutation causes cross-resistance to all PIs [211]. These primary resistance mutations could reduce the catalytic activity via changing the electrostatic and hydrophobic interactions networks to the inhibitor molecule from the mutated amino acids [208,212-214]. Moreover, these mutations also initiate several structural rearrangements throughout the protein globally to adjust the inhibitor binding [215,216]. All the resistance mutations are listed on Table 4 according to the latest update on the drug resistance mutations in HIV-1 [217].

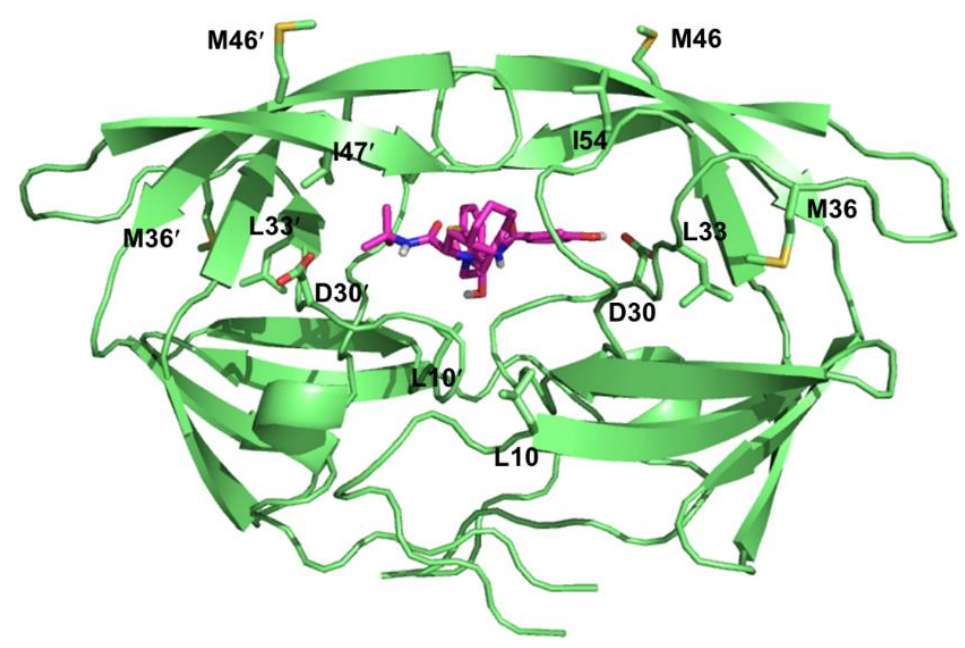

Figure 6. Detailed view of the protease inhibitor binding pocket. Nelfinavir (NFV) is shown as magenta sticks and the NFV-resistant mutation sites are shown in green sticks. PDB 1OHR [218].

Contrary to primary mutations that result in loss of viral fitness, additional secondary mutations at the neighboring non-active site pocket residues compensate for the impaired protease activity via increasing the activity and/or the stability of the protein [219-221]. Besides the secondary mutations, several other molecular mechanisms play an important role in the recovery of viral fitness as well. These mechanisms include the co-evolution of Gag and Gag-Pol cleavage sites [222-226]; mutations that alter the Gag-Pol frameshift leading to an increased expression of pol products [227]; Gag mutations at the non-cleavage sites improve the recovery of viral fitness by improving the access of the viral protease to the cleavage sites [228-230].

Second generation PIs (LPV, FPV, TPV and DRV) possess better pharmacological profiles, less severe side effects and demonstrate improved resistance profiles against the multidrug-resistant protease variants compare to first generation PIs [231-234]. Detailed knowledge of the protease structure has led to the design of new generation inhibitors towards the drug-resistant variants with enhanced binding affinity and a higher genetic barrier for further resistance mutations [235]. For example, a recent study indicated that HIV-1 protease isolates accumulated mutations in the range of 
19 to 32 associated with decreased susceptibility to PIs [211]. Novel protease inhibitor designs illustrate promising antiviral activity profiles against the multidrug resistant HIV-1 variants [236].

Table 4. Major Protease Inhibitor Resistance Mutations.

\begin{tabular}{|c|c|c|c|c|c|c|c|c|}
\hline \multirow{2}{*}{ Consensus } & \multicolumn{8}{|c|}{ Amino acid mutations } \\
\hline & ATV/r & DRV/r & FPV/r & IDV/r & $\mathbf{L P V} / \mathbf{r}$ & NFV & $\mathbf{S Q V} / \mathbf{r}$ & TPV/r \\
\hline L10 & $\mathrm{I}, \mathrm{F}, \mathrm{V}, \mathrm{C}$ & & $\mathrm{F}, \mathrm{I}, \mathrm{R}, \mathrm{V}$ & $\mathrm{I}, \mathrm{R}, \mathrm{V}$ & $\mathrm{I}, \mathrm{R}, \mathrm{V}$ & $\mathrm{F}, \mathrm{I}$ & $\mathrm{I}, \mathrm{R}, \mathrm{V}$ & I \\
\hline V11 & & I & & & & & & \\
\hline G16 & $\mathrm{E}$ & & & & & & & \\
\hline K20 & $\mathrm{R}, \mathrm{M}, \mathrm{I}, \mathrm{T}, \mathrm{V}$ & & & $\mathrm{M}, \mathrm{R}$ & $\mathrm{M}, \mathrm{R}$ & & & \\
\hline L24 & I & & & I & I & & I & \\
\hline D30 & & & & & & $\mathbf{N}$ & & \\
\hline V32 & I & I & I & I & I & & & I \\
\hline L33 & $\mathrm{I}, \mathrm{F}, \mathrm{V}$ & $\mathrm{F}$ & $\mathrm{F}$ & & $\mathrm{F}$ & $\mathrm{F}$ & & $\mathrm{F}$ \\
\hline E34 & $\mathrm{Q}$ & & & & & & & \\
\hline M36 & $\mathrm{I}, \mathrm{L}, \mathrm{V}$ & & & I & & I & & $\mathrm{I}, \mathrm{L}, \mathrm{V}$ \\
\hline K43 & & & & & & & & $\mathrm{T}$ \\
\hline M46 & $\mathrm{I}, \mathrm{L}$ & & $\mathrm{I}, \mathrm{L}$ & $\mathrm{I}, \mathrm{L}$ & $\mathrm{I}, \mathrm{L}$ & $\mathrm{I}, \mathrm{L}$ & & $\mathrm{I}, \mathrm{L}$ \\
\hline $\mathrm{I} 47$ & $\mathrm{~V}$ & $\mathrm{~V}, \mathrm{~A}$ & $\mathbf{V}, \mathbf{A}$ & $\mathrm{V}, \mathrm{A}$ & $\mathrm{V}, \mathrm{A}$ & $\mathrm{V}, \mathrm{A}$ & & $\mathrm{V}, \mathrm{A}$ \\
\hline G48 & $\mathrm{V}, \mathrm{M}$ & & & & $\mathrm{V}, \mathrm{M}$ & $\mathbf{V}, \mathbf{M}$ & $\mathbf{V}, \mathbf{M}$ & \\
\hline $\mathrm{I} 50$ & $\mathbf{L}$ & V & $\mathbf{V}$ & & $\mathrm{V}$ & & & \\
\hline F53 & $\mathrm{L}, \mathrm{Y}$ & & & & L & & & \\
\hline $\mathrm{I} 54$ & $\mathrm{~L}, \mathrm{~V}, \mathrm{M}, \mathrm{T}, \mathrm{A}$ & $\mathrm{M}, \mathrm{L}$ & $\mathbf{L}, \mathrm{V}, \mathbf{M}, \mathrm{T}, \mathrm{A}$ & $\mathrm{V}, \mathrm{T}, \mathrm{A}, \mathrm{L}, \mathrm{M}$ & $\mathrm{V}, \mathrm{L}, \mathrm{A}, \mathrm{M}, \mathrm{T}, \mathrm{S}$ & $\mathrm{V}, \mathrm{T}, \mathrm{A}, \mathrm{L}, \mathrm{M}$ & $\mathrm{V}, \mathrm{L}, \mathrm{T}, \mathrm{A}, \mathrm{M}$ & $\mathrm{A}, \mathrm{M}, \mathrm{V}, \mathrm{T}$ \\
\hline Q58 & & & & & & & & E \\
\hline D60 & E & & & & & & & \\
\hline $\mathrm{I} 62$ & V & & & & & & V & \\
\hline L63 & & & & & $\mathrm{P}$ & & & \\
\hline I64 & $\mathrm{L}, \mathrm{M}, \mathrm{V}$ & & & & & & & \\
\hline H69 & & & & & & & & $\mathrm{K}, \mathrm{R}$ \\
\hline A71 & $\mathrm{V}, \mathrm{I}, \mathrm{T}, \mathrm{L}$ & & & $\mathrm{V}, \mathrm{T}$ & $\mathrm{V}, \mathrm{T}$ & $\mathrm{V}, \mathrm{T}$ & $\mathrm{V}, \mathrm{T}$ & \\
\hline G73 & $\mathrm{C}, \mathrm{S}, \mathrm{T}, \mathrm{A}$ & & S & $\mathrm{S}, \mathrm{A}$ & $\mathrm{S}$ & & $\mathrm{S}$ & \\
\hline L74 & & $\mathrm{P}$ & & & & & & $P$ \\
\hline L76 & & V & $\mathbf{V}$ & $\mathrm{V}$ & V & & & \\
\hline V77 & & & & I & & I & I & \\
\hline V82 & A,T,F,I,S & $\mathrm{F}$ & $\mathrm{A}, \mathbf{F}, \mathrm{S}, \mathrm{T}$ & $\mathrm{A}, \mathrm{F}, \mathrm{T}, \mathrm{S}$ & $\mathrm{A}, \mathrm{F}, \mathrm{T}, \mathrm{S}$ & $\mathrm{A}, \mathrm{F}, \mathrm{T}, \mathrm{S}$ & $\mathrm{A}, \mathrm{F}, \mathrm{T}, \mathrm{S}$ & $\mathrm{L}, \mathrm{T}, \mathrm{S}$ \\
\hline N83 & & & & & & & & D \\
\hline I84 & $\mathbf{V}$ & V & $\mathbf{V}$ & $\mathbf{V}$ & $\mathrm{V}$ & V & $\mathbf{V}$ & V \\
\hline I85 & $\mathrm{V}$ & & & & & & & \\
\hline N88 & $\mathbf{S}$ & & & S & & D,S & S & \\
\hline L89 & & V & & & & & & $\mathrm{I}, \mathrm{M}, \mathrm{V}$ \\
\hline L90 & $\mathrm{M}$ & & M & M & M & $\mathbf{M}$ & M & \\
\hline $\mathrm{I} 93$ & $\mathrm{~L}, \mathrm{M}$ & & & & & & & \\
\hline
\end{tabular}

The resistance mutations are compiled from the updated International Antiviral Society-USA (IAS-USA) and Stanford HIV drug databases. Mutations that are highlighted in bold represent the reduced susceptibility or virological response. 


\subsection{Resistance to HIV-1 Integrase Inhibitors}

HIV-1 integrase is a $32 \mathrm{kDa}$ protein that originates from the cleavage of the Gag-Pol polypeptide precursor mediated by the viral protease [237]. This viral protein consists of three different domains including $\mathrm{N}$ - and C-terminal domains and a catalytic core. All of the domains of integrase are required for its integration activity and this viral protein functions in a multimeric form [238]. HIV-1 integration process occurs in three consecutive steps: formation of the preintegration viral DNA complex, 3'-processing, and strand transfer [239]. The integrase enzyme catalyzes two major reactions after binding to the virally encoded DNA and joints it with host chromosomal DNA. The first reaction is 3'-processing, which consists of the endonucleolytic cleavage of the 3' ends of the viral genome. The cleavage occurs at the conserved $\mathrm{CpA}$ dinucleotide motif, thereby generating CpA-3'-hydroxyl DNA ends that are required for the next strand transfer step. The second catalysis step is strand transfer reaction involves the ligation of the viral 3'-hydroxyl DNA ends to the 5'-DNA phosphate of a host chromosome thus leading to the insertion of viral DNA into the host DNA [240,241]. Clinically approved integrase inhibitors, Raltegravir (RAL), Elvitegravir (EVG), and Dolutegravir (DTG), bind to the catalytic core (amino acids 50-212) of the integrase and target the integration process at the strand transfer step [242]. Catalytic core contains D64, D116, and E152 active site residues that coordinate the divalent cations required for 3'-processing, and strand transfer [243]. Drug resistant mutations against integrase inhibitors are determined via drug selection and viral fitness studies. Table 5 lists the major integrase inhibitor resistance mutations against the clinically approved drugs.

Resistance to RAL generally arises from three major mutation sites at positions Y143, Q148, and N155 with the accumulation of one or more additional residue changes in their vicinity [244]. Clinical data on RAL resistance has demonstrated the development of two main Q148 and N155 resistance pathways producing high-level phenotypic resistance to all approved integrase inhibitors [245,246]. These mutation pathways are thought to be mutually exclusive and do not appear in the same viral genome. Even though the Q148 and N155 pathways are predominant, there is another Y143 pathway that has been detected in patients [247]. Q148 pathway includes Q148H/K/R substitutions accompanied with subsequent mutations like L74M, E92Q, T97A, G136R, E138A/K, G140A/S, and V151I [244]. Alternatively, the N155 pathway predominantly consists of N155H mutation and occasionally associated with L74M, T97A, E157Q, and G163K/R [247]. The infrequent Y143 pathway consists of $\mathrm{Y} 143 \mathrm{C} / \mathrm{H} / \mathrm{R}$ mutations and L74A/I, T97A, G163K/R accessory mutations [245,246]. Furthermore, in vitro assays showed that G140S/Q148H double mutant and E92Q mutation desensitized the RAL activity by 7-8 fold and the N155H mutant was 14 times more resistant to RAL compare to WT integrase [248]. It has been also suggested that G140S substitution in the double mutants increases the viral fitness produced by Q148K and Q148H [249,250].

EVG was approved in 2012 and formulated as a partner agent to FTC and EFV in Stribild ${ }^{\circledR}$ (quad pill) together with cobicistat as a pharmacokinetic enhancer for EVG[251]. Unfortunately, EVG shows a similar resistance mutation profile in comparison with RAL, because the major mutations at Q148 and N155 pathways along with their accessory mutations have also been selected by EVG [252,253]. However, the third Y143 mutation pathway does not confer EVG cross-resistance. In contrast, there are specific mutation sites that confer resistance to only EVG such as T66 position 
mutations (T66I/A/K). In addition, E92Q mutation, which is located at the active site of integrase, causes higher resistance to EVG than RAL [254].

DTG is the latest approved drug against HIV infection and effective against the RAL and EVG resistant clinical isolates of HIV-1 including Q148K, N155H, Y143, and G140S/Q148H mutations [255]. Therefore, it has been suggested that DTG has a higher genetic barrier to resistance than RAL and EVG [252]. One reason for this outcome could be the determined slow dissociation rate $\left(k_{\text {off }}\right)$ of DTG from integrase-DNA complex in comparison to RAL and EVG [256]. Although DTG retains its antiviral activity against majority of the single mutation variants [257], R263K mutation is found to confer low-level resistance to DTG and cause decreased integration in cell culture [258]. The same mutation has been reported in a clinical study [259]. Furthermore, R263K mutation in combination with H51Y showed decreased susceptibility to DTG while declining viral fitness via reduced integration and impaired viral replication [260]. Secondary mutations M50I and E138K compensate for this reduced viral replication. Another resistance mutation that has been selected in cell culture after DTG treatment is G118R mutation [261]. Remarkably, viruses containing R263K and G118R DTG resistant mutations alone or along with secondary mutations were impaired in their ability to develop resistance against 3TC and NVP in in vitro studies [262]. In summary, recent insights on drug resistance have suggested that cross-resistance is a big hurdle and to avoid this problem more second generation integrase inhibitors like DTG should be designed.

Table 5. Major Integrase Inhibitor Resistance Mutations.

\begin{tabular}{cccc}
\hline \multirow{2}{*}{ Consensus } & \multicolumn{3}{c}{ Amino acid mutations } \\
\cline { 2 - 4 } & RAL & EVG & DTG \\
\hline T66 & A & I,A,K & \\
L74 & M & & \\
E92 & Q & Q,G & Q \\
T97 & A & A & \\
E138 & A,K & K,A & A,K \\
G140 & A,S,C & A,S,C & A,S,C \\
Y143 & R,H,C & & \\
S147 & & G & \\
Q148 & H,K,R & $\mathbf{R , H , K}$ & H,R,K \\
N155 & $\mathbf{H}$ & $\mathbf{H}$ & \\
\hline
\end{tabular}

The resistance mutations are compiled from the updated International Antiviral Society-USA (IAS-USA) and Stanford HIV drug databases. Mutations that are highlighted in bold represent the reduced susceptibility or virological response.

\subsection{Resistance to Viral Entry Inhibitors}

HIV entry is a combination of multi-step interrelated processes that involves coordinated multiple sequential interactions between the viral gp120 and gp41 and host surface proteins [263]. Even though there are several potential targets during the entry processes, only two different classes of entry inhibitors were approved by FDA to block viral entry into cells. The first drug Maraviroc (MVC) is a chemokine receptor antagonist targeting the interaction between gp120 and CCR5 chemokine coreceptor after gp120 binds to the CD4 receptor on the host cell surface [264]. Two classes of viruses were identified and classified as T-tropic and M-tropic viruses infecting CD4+ $\mathrm{T}$ cells and 
macrophages, respectively [265-267]. M-tropic viruses use CCR5 as the preferred coreceptor [268], whereas T-tropic viruses utilize CXCR4 as a coreceptor for viral entry [269]. MVC is a selective CCR5 antagonist that targets host protein contrary to the other anti-HIV drugs [270]. MVC binds to an allosteric hydrophobic pocket formed by the transmembrane helices of CCR5 and inhibits HIV-1 entry through altering the conformation of the receptor so that it can no longer be recognized by gp120 [271,272]. Despite its successful antiviral efficacy in clinical trials [273,274], several in vitro and in vivo studies demonstrated diverse resistance mechanisms against MVC therapy. One resistance mechanism that HIV utilizes to evade MVC treatment is the tropism switch by utilizing CXCR4 coreceptor instead of CCR5 to enter the cell [275]. According to the in vitro studies, selection of CXCR4 tropic viruses may not be main mechanism of escape [276-278]. However, the major resistance mechanism against MVC is emergence of multiple mutations in the HIV-1 envelope protein that allow the virus to use the MVC occupied CCR5 coreceptor [279,280]. The majority of these mutations were mostly located in the V3 loop region of gp120 [279,281,282]. In conclusion, the results from these studies suggest that MVC-resistant virus could bind to CCR5 coreceptor both in a drug free conformation and MVC-bound conformation. Moreover, HIV-1 may switch coreceptor usage to CXCR4 if CXCR4 using species were present during the initial drug treatment period [275].

The other class of entry inhibitor, Enfuvirtide, is a fusion inhibitor that targets the fusion activity of gp41 [283]. HIV-1 gp41 is responsible for anchoring the envelope complex to the cell membrane, thereby bringing the virus and target cell into close proximity and assisting their fusion by further conformational rearrangement in its structure. During membrane fusion, heptad repeat 2 (HR2) region of gp41 folds onto the heptad repeat 1 (HR1) hydrophobic region thereby shortening the molecule. Enfuvirtide is a 36 amino acids long synthetic peptide derived from the C-terminal region of HR2 [284]. Enfuvirtide shows its antiviral activity through binding to HR1 region of gp41 and blocking the virus from infecting the cell. Predictably, viral resistance to Enfuvirtide emerges through a stretch of amino acids that are located in the HR1 region as shown in Table 6 [285].

Table 6. Major Mutations in The Envelope Gene Associated with Resistance to Enfuvirtide.

\begin{tabular}{cc}
\hline \multirow{2}{*}{ Consensus } & Amino acid mutations \\
\cline { 2 - 2 } & Enfuvirtide \\
\hline G36 & D,S \\
I37 & V \\
V38 & A,M,E \\
Q39 & R \\
Q40 & H \\
N42 & T \\
N43 & D \\
\hline
\end{tabular}

Specifically, amino acid positions G36, I37, and V38 were shown to confer resistance or sensitivity to Enfuvirtide. In vivo and other in vitro studies have confirmed the mutations within these gp41 residues 36-38, as well as some other mutation sites along the HR1 region [286-293]. These mutations emerge quickly upon drug treatment and are mostly found in various HIV subtypes. In addition, several combinations of two mutations were detected that lead to strong resistance to the inhibitor such as G36D/N42T, G36V/N42D, I37M/N43D, V38A/N42D, V38A/N42T, V38A/L44D, V38E/N42S, and Q41R/N43D [294-297]. The resistance mutations on HR1 region that Enfurvitide binds destabilize 
the six-helix bundle structure of gp41 and thus causing decreased binding affinity for the inhibitor [285,296,298]. While efficient discrimination against Enfurvitide could be established by these mutations, they could also reduce the viral fitness by disrupting the interactions between the mutated HR1 and the endogenous HR2 [289,299,300]. In order to address these destabilizing HR1 mutations, new mutations in HR2 region could emerge to compensate for the fitness loss later in the treatment. Several x-ray crystallographic studies have shown that HR2 mutations could enhance the stability of the six-helix bundle via direct interactions to the HR1 mutated residue [301,302].

\section{Monitoring Antiretroviral Drug Resistance}

HIV treatment options have become more effective at delaying the drug resistance evolution during the last decades. However, there is still room to improve the emergence of resistance since acquired drug resistance still occurs in the clinic. Routine viral load monitoring and viral genotyping help the clinicians to find better drug choices and combinations with minimum risk of drug resistance. It also prevents unnecessary treatment switches and accumulation of drug resistance in patients. Especially in developing countries, low-cost technologies to diagnose and monitor HIV infection are crucial in health care settings [303]. For example, there has been a slight increase in the prevalence of NNRTI resistance mutations, which was attributed to infection with resistant viruses in low to middle income countries where NNRTI regimens are very common and resistance monitoring is absent [304]. Therefore, more efforts have been directed to develop point-of-care (POC) technologies that are affordable, robust, portable and easy to use with high accuracy results to aid the decision making for patients who are failing therapy in resource-limited settings. For instance, a new nucleic acid-based POC platform, simple amplification-based assay (SAMBA), has been described for HIV-1 testing [305]. The SAMBA test relies on isothermal amplification with a visual readout, which makes it suitable for resource poor settings. All the currently available POC technologies have been outlined in a recent review article [303]. Viral load monitoring is important to identify individuals who are not adherent to their treatment and to switch treatment options according to the changes in viral load over time [306]. If the viral load rises above 200 copies $/ \mathrm{mL}$, it might be sign of emergence of drug resistance mutations. For HIV-1 genotyping, there are several commercial or laboratory-developed tests are available to detect the resistance associated mutations. These tests mainly utilize PCR amplification and nucleotide sequencing of viral genes such as reverse transcriptase, protease, and integrase [307]. The WHO and International AIDS Society-USA Panel recommends antiretroviral drug testing as a routine management of the viral infection in developing countries. Coreceptor tropism testing is also becoming available since new drugs are entering to the pipeline. More effort should be placed in improving the sensitivity and accuracy of these assays to better detect the minor variants that might be clinically significant.

\section{Conclusions and Future Directions}

Recent clinical data and experimental studies have demonstrated that HIV-1 infection could be successfully treated with the minimized resistance mutations [308,309]. These new drugs have superior antiviral efficacy with high viral suppression and higher genetic barriers against the evolution of drug resistance. Moreover, the improved pharmacokinetics and bioavailability properties of 
currently available drugs have allowed simplification of their dosing regimens in combination therapies. Even though there is a widespread shift in basic research towards finding a cure for HIV or developing new drugs or formulations for prevention, we still have to treat infected patients with limited therapy options because of the developed drug resistance. Viral load monitoring is still not available for everyone in limited resource settings. These patients could stay on the failing treatment and acquire more drug resistance mutations, which could compromise the second-line treatment options as well. In order to solve the drug resistance problem, the availability of newer drugs and monitoring needs to be improved drastically. Also, there is always a possibility of therapy failure for current drugs and no one can predict if these drugs will retain their efficacies for many years in the future. Therefore, we still need to put a lot of effort on finding new drugs with novel mechanism of actions and exploit novel druggable viral targets that would give us the upper hand in the battle against HIV infection.

\section{Acknowledgments}

This work was supported by the National Institutes of Health Grant R01 GM49551.

\section{Conflicts of Interest}

The authors declare no conflict of interest.

\section{References}

1. Barre-Sinoussi, F. Hiv as the cause of aids. Lancet 1996, 348, 31-35.

2. WHO. Unaids Report on the Global Aids Epidemic 2013. Available onine: http://www.unaids.org/ en/media/unaids/contentassets/documents/epidemiology/2013/gr2013/UNAIDS_Global_Report_ 2013_en.pdf (accessed on 16 June 2014).

3. De Clercq, E. Human viral diseases: What is next for antiviral drug discovery? Curr. Opin. Virol. 2012, 2, 572-579.

4. De Clercq, E. Anti-hiv drugs: 25 compounds approved within 25 years after the discovery of hiv. Int. J. Antimicrob. Agents 2009, 33, 307-320.

5. Chen, R.; Quinones-Mateu, M.E.; Mansky, L.M. Hiv-1 mutagenesis during antiretroviral therapy: Implications for successful drug treatment. Front. Biosci. 2005, 10, 743-750.

6. Burke, D.S. Recombination in hiv: An important viral evolutionary strategy. Emerg. Infect. Dis. 1997, 3, 253-259.

7. Mansky, L.M.; Temin, H.M. Lower in vivo mutation rate of human immunodeficiency virus type 1 than that predicted from the fidelity of purified reverse transcriptase. J. Virol. 1995, 69, 5087-5094.

8. Sanjuan, R.; Nebot, M.R.; Chirico, N.; Mansky, L.M.; Belshaw, R. Viral mutation rates. J. Virol. 2010, 84, 9733-9748.

9. Ho, D.D.; Neumann, A.U.; Perelson, A.S.; Chen, W.; Leonard, J.M.; Markowitz, M. Rapid turnover of plasma virions and cd4 lymphocytes in hiv-1 infection. Nature 1995, 373, 123-126. 
10. Wei, X.; Ghosh, S.K.; Taylor, M.E.; Johnson, V.A.; Emini, E.A.; Deutsch, P.; Lifson, J.D.; Bonhoeffer, S.; Nowak, M.A.; Hahn, B.H.; et al. Viral dynamics in human immunodeficiency virus type 1 infection. Nature 1995, 373, 117-122.

11. Perelson, A.S.; Neumann, A.U.; Markowitz, M.; Leonard, J.M.; Ho, D.D. Hiv-1 dynamics in vivo: Virion clearance rate, infected cell life-span, and viral generation time. Science 1996, 271, 1582-1586.

12. Chun, T.W.; Carruth, L.; Finzi, D.; Shen, X.; DiGiuseppe, J.A.; Taylor, H.; Hermankova, M.; Chadwick, K.; Margolick, J.; Quinn, T.C.; et al. Quantification of latent tissue reservoirs and total body viral load in hiv-1 infection. Nature 1997, 387, 183-188.

13. Jung, A.; Maier, R.; Vartanian, J.P.; Bocharov, G.; Jung, V.; Fischer, U.; Meese, E.; Wain-Hobson, S.; Meyerhans, A. Recombination: Multiply infected spleen cells in hiv patients. Nature 2002, $418,144$.

14. Keele, B.F.; Giorgi, E.E.; Salazar-Gonzalez, J.F.; Decker, J.M.; Pham, K.T.; Salazar, M.G.; Sun, C.; Grayson, T.; Wang, S.; Li, H.; et al. Identification and characterization of transmitted and early founder virus envelopes in primary hiv-1 infection. Proc. Natl. Acad. Sci. USA 2008, 105, 7552-7557.

15. Temin, H.M. Is hiv unique or merely different? J. Acquir. Immune Defic. Syndr. 1989, 2, 1-9.

16. Coffin, J.M. Hiv population dynamics in vivo: Implications for genetic variation, pathogenesis, and therapy. Science 1995, 267, 483-489.

17. Domingo, E.; Holland, J.J. Rna virus mutations and fitness for survival. Annu. Rev. Microbiol. 1997, 51, 151-178.

18. Eigen, M. On the nature of virus quasispecies. Trends Microbiol. 1996, 4, 216-218.

19. Holland, J.J.; de la Torre, J.C.; Steinhauer, D.A. Rna virus populations as quasispecies. Curr. Top. Microbiol. Immunol. 1992, 176, 1-20.

20. Eigen, M.; Schuster, P. The Hypercycle: A Principle of Natural Self-Organization; Springer: Berlin, Germany, 1979.

21. Domingo, E.; Wu, H.; Lien, E.J.; Lien, L.L.; Schultz, R.M.; Ram, V.J.; Spence, P.; Gupta, S.P.; Bhat, S.P.; Villarreal, E.C. Quasispecies and the development of new antiviral strategies. In Progress Drug Research; Jucker, E., Ed.; Birkhäuser Verlag: Basel, Switzerland, 2003; Volume 60, pp. 133-158.

22. Biebricher, C.K.; Eigen, M. What is a quasispecies? Curr. Top. Microbiol. Immunol. 2006, 299, 1-31.

23. Rouzine, I.M.; Brunet, E.; Wilke, C.O. The traveling-wave approach to asexual evolution: Muller's ratchet and speed of adaptation. Theor. Popul. Biol. 2008, 73, 24-46.

24. Bull, J.J.; Sanjuan, R.; Wilke, C.O. Theory of lethal mutagenesis for viruses. J. Virol. 2007, 81, 2930-2939.

25. Mansky, L.M. Retrovirus mutation rates and their role in genetic variation. J. Gen. Virol. 1998, 79 (Pt 6), 1337-1345.

26. Nowak, M.A.; Anderson, R.M.; McLean, A.R.; Wolfs, T.F.; Goudsmit, J.; May, R.M. Antigenic diversity thresholds and the development of aids. Science 1991, 254, 963-969.

27. Mansky, L.M. Hiv mutagenesis and the evolution of antiretroviral drug resistance. Drug Resist. Updates 2002, 5, 219-223. 
28. Preston, B.D.; Dougherty, J.P. Mechanisms of retroviral mutation. Trends Microbiol. 1996, 4, $16-21$.

29. Menendez-Arias, L. Molecular basis of fidelity of DNA synthesis and nucleotide specificity of retroviral reverse transcriptases. Prog. Nucleic Acid Res. Mol. Biol. 2002, 71, 91-147.

30. Jonckheere, H.; Anne, J.; de Clercq, E. The hiv-1 reverse transcription (rt) process as target for $\mathrm{rt}$ inhibitors. Med. Res. Rev. 2000, 20, 129-154.

31. Roberts, J.D.; Bebenek, K.; Kunkel, T.A. The accuracy of reverse transcriptase from hiv-1. Science 1988, 242, 1171-1173.

32. Preston, B.D.; Poiesz, B.J.; Loeb, L.A. Fidelity of hiv-1 reverse transcriptase. Science 1988, 242, 1168-1171.

33. Roberts, J.D.; Preston, B.D.; Johnston, L.A.; Soni, A.; Loeb, L.A.; Kunkel, T.A. Fidelity of two retroviral reverse transcriptases during DNA-dependent DNA synthesis in vitro. Mol. Cell. Biol. 1989, 9, 469-476.

34. Steinhauer, D.A.; Domingo, E.; Holland, J.J. Lack of evidence for proofreading mechanisms associated with an rna virus polymerase. Gene 1992, 122, 281-288.

35. Zhang, J. Host rna polymerase ii makes minimal contributions to retroviral frame-shift mutations. J. Gen. Virol. 2004, 85, 2389-2395.

36. O’Neil, P.K.; Sun, G.; Yu, H.; Ron, Y.; Dougherty, J.P.; Preston, B.D. Mutational analysis of hiv-1 long terminal repeats to explore the relative contribution of reverse transcriptase and rna polymerase ii to viral mutagenesis. J. Biol. Chem. 2002, 277, 38053-38061.

37. Harris, R.S.; Liddament, M.T. Retroviral restriction by apobec proteins. Nat. Rev. Immunol. 2004, 4, 868-877.

38. Malim, M.H.; Emerman, M. Hiv-1 accessory proteins-Ensuring viral survival in a hostile environment. Cell Host Microbe 2008, 3, 388-398.

39. Chiu, Y.L.; Greene, W.C. The apobec3 cytidine deaminases: An innate defensive network opposing exogenous retroviruses and endogenous retroelements. Annu. Rev. Immunol. 2008, 26, 317-353.

40. Sheehy, A.M.; Gaddis, N.C.; Choi, J.D.; Malim, M.H. Isolation of a human gene that inhibits hiv-1 infection and is suppressed by the viral vif protein. Nature 2002, 418, 646-650.

41. Mangeat, B.; Turelli, P.; Caron, G.; Friedli, M.; Perrin, L.; Trono, D. Broad antiretroviral defence by human apobec3g through lethal editing of nascent reverse transcripts. Nature 2003, 424, 99-103.

42. Mariani, R.; Chen, D.; Schrofelbauer, B.; Navarro, F.; Konig, R.; Bollman, B.; Munk, C.; Nymark-McMahon, H.; Landau, N.R. Species-specific exclusion of apobec3g from hiv-1 virions by vif. Cell 2003, 114, 21-31.

43. KewalRamani, V.N.; Coffin, J.M. Virology. Weapons of mutational destruction. Science 2003, 301, 923-925.

44. Bhagwat, A.S. DNA-cytosine deaminases: From antibody maturation to antiviral defense. DNA Repair 2004, 3, 85-89.

45. Aires da Silva, F.; Santa-Marta, M.; Freitas-Vieira, A.; Mascarenhas, P.; Barahona, I.; Moniz-Pereira, J.; Gabuzda, D.; Goncalves, J. Camelized rabbit-derived vh single-domain intrabodies against vif strongly neutralize hiv-1 infectivity. J. Mol. Biol. 2004, 340, 525-542. 
46. Harris, R.S.; Bishop, K.N.; Sheehy, A.M.; Craig, H.M.; Petersen-Mahrt, S.K.; Watt, I.N.; Neuberger, M.S.; Malim, M.H. DNA deamination mediates innate immunity to retroviral infection. Cell 2003, 113, 803-809.

47. Lecossier, D.; Bouchonnet, F.; Clavel, F.; Hance, A.J. Hypermutation of hiv-1 DNA in the absence of the vif protein. Science 2003, 300, 1112.

48. Zhang, H.; Yang, B.; Pomerantz, R.J.; Zhang, C.; Arunachalam, S.C.; Gao, L. The cytidine deaminase cem15 induces hypermutation in newly synthesized hiv-1 DNA. Nature 2003, 424, 94-98.

49. Goff, S.P. Death by deamination: A novel host restriction system for hiv-1. Cell 2003, 114, 281-283.

50. Lavens, D.; Peelman, F.; van der Heyden, J.; Uyttendaele, I.; Catteeuw, D.; Verhee, A.; van Schoubroeck, B.; Kurth, J.; Hallenberger, S.; Clayton, R.; et al. Definition of the interacting interfaces of apobec3g and hiv-1 vif using mappit mutagenesis analysis. Nucleic Acids Res. 2010, 38, 1902-1912.

51. Goncalves, J.; Santa-Marta, M. Hiv-1 vif and apobec3g: Multiple roads to one goal. Retrovirology 2004, 1, 28.

52. Cadima-Couto, I.; Goncalves, J. Towards inhibition of vif-apobec3g interaction: Which protein to target? Adv. Virol. 2010, 2010, 649315.

53. Munk, C.; Jensen, B.E.; Zielonka, J.; Haussinger, D.; Kamp, C. Running loose or getting lost: How hiv-1 counters and capitalizes on apobec3-induced mutagenesis through its vif protein. Viruses 2012, 4, 3132-3161.

54. Orr, H.A. The rate of adaptation in asexuals. Genetics 2000, 155, 961-968.

55. Zhuang, J.; Jetzt, A.E.; Sun, G.; Yu, H.; Klarmann, G.; Ron, Y.; Preston, B.D.; Dougherty, J.P. Human immunodeficiency virus type 1 recombination: Rate, fidelity, and putative hot spots. J. Virol. 2002, 76, 11273-11282.

56. Mulder, L.C.; Harari, A.; Simon, V. Cytidine deamination induced hiv-1 drug resistance. Proc. Natl. Acad. Sci. USA 2008, 105, 5501-5506.

57. Hu, W.S.; Temin, H.M. Retroviral recombination and reverse transcription. Science 1990, 250, 1227-1233.

58. Zhang, J.; Tang, L.Y.; Li, T.; Ma, Y.; Sapp, C.M. Most retroviral recombinations occur during minus-strand DNA synthesis. J. Virol. 2000, 74, 2313-2322.

59. Yu, H.; Jetzt, A.E.; Ron, Y.; Preston, B.D.; Dougherty, J.P. The nature of human immunodeficiency virus type 1 strand transfers. J. Biol. Chem. 1998, 273, 28384-28391.

60. Jetzt, A.E.; Yu, H.; Klarmann, G.J.; Ron, Y.; Preston, B.D.; Dougherty, J.P. High rate of recombination throughout the human immunodeficiency virus type 1 genome. J. Virol. 2000, 74, 1234-1240.

61. Levy, D.N.; Aldrovandi, G.M.; Kutsch, O.; Shaw, G.M. Dynamics of hiv-1 recombination in its natural target cells. Proc. Natl. Acad. Sci. USA 2004, 101, 4204-4209.

62. Althaus, C.L.; Bonhoeffer, S. Stochastic interplay between mutation and recombination during the acquisition of drug resistance mutations in human immunodeficiency virus type 1. J. Virol. 2005, 79, 13572-13578. 
63. Nora, T.; Charpentier, C.; Tenaillon, O.; Hoede, C.; Clavel, F.; Hance, A.J. Contribution of recombination to the evolution of human immunodeficiency viruses expressing resistance to antiretroviral treatment. J. Virol. 2007, 81, 7620-7628.

64. Bretscher, M.T.; Althaus, C.L.; Muller, V.; Bonhoeffer, S. Recombination in hiv and the evolution of drug resistance: For better or for worse? BioEssays 2004, 26, 180-188.

65. Perales, C.; Iranzo, J.; Manrubia, S.C.; Domingo, E. The impact of quasispecies dynamics on the use of therapeutics. Trends Microbiol. 2012, 20, 595-603.

66. Mullins, J.I.; Jensen, M.A. Evolutionary dynamics of hiv-1 and the control of aids. Curr. Top. Microbiol. Immunol. 2006, 299, 171-192.

67. Gao, F.; Chen, Y.; Levy, D.N.; Conway, J.A.; Kepler, T.B.; Hui, H. Unselected mutations in the human immunodeficiency virus type 1 genome are mostly nons ynonymous and often deleterious. J. Virol. 2004, 78, 2426-2433.

68. Loeb, L.A.; Essigmann, J.M.; Kazazi, F.; Zhang, J.; Rose, K.D.; Mullins, J.I. Lethal mutagenesis of hiv with mutagenic nucleoside analogs. Proc. Natl. Acad. Sci. USA 1999, 96, 1492-1497.

69. Grande-Perez, A.; Lazaro, E.; Lowenstein, P.; Domingo, E.; Manrubia, S.C. Suppression of viral infectivity through lethal defection. Proc. Natl. Acad. Sci. USA 2005, 102, 4448-4452.

70. Huber-Ruano, I.; Pastor-Anglada, M. Transport of nucleoside analogs across the plasma membrane: A clue to understanding drug-induced cytotoxicity. Curr. Drug Metab. 2009, 10, 347-358.

71. Eriksson, S.; Wang, L. The role of the cellular deoxynucleoside kinases in activation of nucleoside analogs used in chemotherapy. In Recent Advances in Nucleosides: Chemistry and Chemotherapy; Chu, C.K., Ed.; Elsevier: New York, NY, USA, 2002; pp. 465-468.

72. Loeb, L.A.; Mullins, J.I. Lethal mutagenesis of hiv by mutagenic ribonucleoside analogs. AIDS Res. Hum. Retrovir. 2000, 16, 1-3.

73. Kamath-Loeb, A.S.; Hizi, A.; Tabone, J.; Solomon, M.S.; Loeb, L.A. Inefficient repair of rna $\mathrm{x}$ DNA hybrids. Eur. J. Biochem./FEBS 1997, 250, 492-501.

74. Suen, W.; Spiro, T.G.; Sowers, L.C.; Fresco, J.R. Identification by uv resonance raman spectroscopy of an imino tautomer of 5-hydroxy-2'-deoxycytidine, a powerful base analog transition mutagen with a much higher unfavored tautomer frequency than that of the natural residue 2'-deoxycytidine. Proc. Natl. Acad. Sci. USA 1999, 96, 4500-4505.

75. Smith, R.A.; Loeb, L.A.; Preston, B.D. Lethal mutagenesis of hiv. Virus Res. 2005, 107, 215-228.

76. Anderson, J.P.; Daifuku, R.; Loeb, L.A. Viral error catastrophe by mutagenic nucleosides. Annu. Rev. Microbiol. 2004, 58, 183-205.

77. Issa, J.P.; Kantarjian, H. Azacitidine. Nat. Rev. 2005, Suppl, S6-S7.

78. Bouchard, J.; Walker, M.C.; Leclerc, J.M.; Lapointe, N.; Beaulieu, R.; Thibodeau, L. 5azacytidine and 5-azadeoxycytidine inhibit human immunodeficiency virus type 1 replication in vitro. Antimicrob. Agents Chemother. 1990, 34, 206-209.

79. Dapp, M.J.; Clouser, C.L.; Patterson, S.; Mansky, L.M. 5-azacytidine can induce lethal mutagenesis in human immunodeficiency virus type 1. J. Virol. 2009, 83, 11950-11958.

80. Clouser, C.L.; Patterson, S.E.; Mansky, L.M. Exploiting drug repositioning for discovery of a novel hiv combination therapy. J. Virol. 2010, 84, 9301-9309. 
81. Rogstad, D.K.; Herring, J.L.; Theruvathu, J.A.; Burdzy, A.; Perry, C.C.; Neidigh, J.W.; Sowers, L.C. Chemical decomposition of 5-aza-2'-deoxycytidine (decitabine): Kinetic analyses and identification of products by nmr, hplc, and mass spectrometry. Chem. Res. Toxicol. 2009, 22, 1194-1204.

82. Jackson-Grusby, L.; Laird, P.W.; Magge, S.N.; Moeller, B.J.; Jaenisch, R. Mutagenicity of 5-aza-2'-deoxycytidine is mediated by the mammalian DNA methyltransferase. Proc. Natl. Acad. Sci. USA 1997, 94, 4681-4685.

83. Pathak, V.K.; Temin, H.M. 5-azacytidine and rna secondary structure increase the retrovirus mutation rate. J. Virol. 1992, 66, 3093-3100.

84. Harris, K.S.; Brabant, W.; Styrchak, S.; Gall, A.; Daifuku, R. Kp-1212/1461, a nucleoside designed for the treatment of hiv by viral mutagenesis. Antivir. Res. 2005, 67, 1-9.

85. Murakami, E.; Basavapathruni, A.; Bradley, W.D.; Anderson, K.S. Mechanism of action of a novel viral mutagenic covert nucleotide: Molecular interactions with hiv-1 reverse transcriptase and host cell DNA polymerases. Antivir. Res. 2005, 67, 10-17.

86. Johnson, A.A.; Ray, A.S.; Hanes, J.; Suo, Z.; Colacino, J.M.; Anderson, K.S.; Johnson, K.A. Toxicity of antiviral nucleoside analogs and the human mitochondrial DNA polymerase. J. Biol. Chem. 2001, 276, 40847-40857.

87. Clay, P.G.; McRae, M.; Laurent, J.P. Safety, tolerability, and pharmacokinetics of kp-1461 in phase i clinical studies: A single oral dose study in non-hiv-infected adults, and a 14-day dose-escalating study in highly antiretroviral-experienced hiv-infected adults. J. Int. Assoc. Physicians AIDS Care 2011, 10, 232-238.

88. Mullins, J.I.; Heath, L.; Hughes, J.P.; Kicha, J.; Styrchak, S.; Wong, K.G.; Rao, U.; Hansen, A.; Harris, K.S.; Laurent, J.P.; et al. Mutation of hiv-1 genomes in a clinical population treated with the mutagenic nucleoside kp1461. PLoS One 2011, 6, e15135.

89. Hicks, C.; Clay, P.; Redfield, R.; Lalezari, J.; Liporace, R.; Schneider, S.; Sension, M.; McRae, M.; Laurent, J.P. Safety, tolerability, and efficacy of kp-1461 as monotherapy for 124 days in antiretroviral-experienced, hiv type 1-infected subjects. AIDS Res. Hum. Retrovir. 2013, 29, 250-255.

90. Mehellou, Y.; de Clercq, E. Twenty-six years of anti-hiv drug discovery: Where do we stand and where do we go? J. Med. Chem. 2010, 53, 521-538.

91. Sarafianos, S.G.; Marchand, B.; Das, K.; Himmel, D.M.; Parniak, M.A.; Hughes, S.H.; Arnold, E. Structure and function of hiv-1 reverse transcriptase: Molecular mechanisms of polymerization and inhibition. J. Mol. Biol. 2009, 385, 693-713.

92. Arion, D.; Kaushik, N.; McCormick, S.; Borkow, G.; Parniak, M.A. Phenotypic mechanism of hiv-1 resistance to 3'-azido-3'-deoxythymidine (azt): Increased polymerization processivity and enhanced sensitivity to pyrophosphate of the mutant viral reverse transcriptase. Biochemistry 1998, 37, 15908-15917.

93. Meyer, P.R.; Matsuura, S.E.; So, A.G.; Scott, W.A. Unblocking of chain-terminated primer by hiv-1 reverse transcriptase through a nucleotide-dependent mechanism. Proc. Natl. Acad. Sci. USA 1998, 95, 13471-13476. 
94. Huang, H.; Chopra, R.; Verdine, G.L.; Harrison, S.C. Structure of a covalently trapped catalytic complex of hiv-1 reverse transcriptase: Implicaiton fro drug resistance. Science 1998, 282, 1669-1675.

95. Huang, H.; Chopra, R.; Verdine, G.L.; Harrison, S.C. Structure of a covalently trapped catalytic complex of hiv-1 reverse transcriptase: Implications for drug resistance. Science 1998, 282, 1669-1675.

96. Selmi, B.; Boretto, J.; Sarfati, S.R.; Guerreiro, C.; Canard, B. Mechanism-based suppression of dideoxynucleotide resistance by $\mathrm{k} 65 \mathrm{r}$ human immunodeficiency virus reverse transcriptase using an alpha-boranophosphate nucleoside analogue. J. Biol Chem. 2001, 276, 48466-48472.

97. Deval, J.; Alvarez, K.; Selmi, B.; Bermond, M.; Boretto, J.; Guerreiro, C.; Mulard, L.; Canard, B. Mechanistic insights into the suppression of drug resistance by human immunodeficiency virus type 1 reverse transcriptase using alpha-boranophosphate nucleoside analogs. J. Biol. Chem. 2005, 280, 3838-3846.

98. Sluis-Cremer, N.; Sheen, C.W.; Zelina, S.; Torres, P.S.; Parikh, U.M.; Mellors, J.W. Molecular mechanism by which the $\mathrm{k} 70 \mathrm{e}$ mutation in human immunodeficiency virus type 1 reverse transcriptase confers resistance to nucleoside reverse transcriptase inhibitors. Antimicrob. Agents Chemother. 2007, 51, 48-53.

99. Deval, J.; White, K.L.; Miller, M.D.; Parkin, N.T.; Courcambeck, J.; Halfon, P.; Selmi, B.; Boretto, J.; Canard, B. Mechanistic basis for reduced viral and enzymatic fitness of hiv-1 reverse transcriptase containing both k65r and m184v mutations. J. Biol. Chem. 2004, 279, 509-516.

100. Feng, J.Y.; Myrick, F.T.; Margot, N.A.; Mulamba, G.B.; Rimsky, L.; Borroto-Esoda, K.; Selmi, B.; Canard, B. Virologic and enzymatic studies revealing the mechanism of k65r- and q151m-associated hiv-1 drug resistance towards emtricitabine and lamivudine. Nucleosides Nucleotides Nucleic Acids 2006, 25, 89-107.

101. Sarafianos, S.G.; Das, K.; Clark, A.D., Jr.; Ding, J.; Boyer, P.L.; Hughes, S.H.; Arnold, E. Lamivudine (3tc) resistance in hiv-1 reverse transcriptase involves steric hindrance with beta-branched amino acids. Proc. Natl. Acad. Sci. USA 1999, 96, 10027-10032.

102. Ray, A.S.; Murakami, E.; Peterson, C.N.; Shi, J.; Schinazi, R.F.; Anderson, K.S. Interactions of enantiomers of 2',3'-didehydro-2',3'-dideoxy-fluorocytidine with wild type and m184v mutant hiv-1 reverse transcriptase. Antivir. Res. 2002, 56, 189-205.

103. Gao, H.Q.; Boyer, P.L.; Sarafianos, S.G.; Arnold, E.; Hughes, S.H. The role of steric hindrance in 3tc resistance of human immunodeficiency virus type-1 reverse transcriptase. J. Mol. Biol. 2000, 300, 403-418.

104. Wei, X.; Liang, C.; Gotte, M.; Wainberg, M.A. Negative effect of the m184v mutation in hiv-1 reverse transcriptase on initiation of viral DNA synthesis. Virology 2003, 311, 202-212.

105. Van Cor-Hosmer, S.K.; Daddacha, W.; Kim, B. Mechanistic interplay among the m184i hiv-1 reverse transcriptase mutant, the central polypurine tract, cellular dntp concentrations and drug sensitivity. Virology 2010, 406, 253-260.

106. Marcelin, A.G.; Charpentier, C.; Wirden, M.; Landman, R.; Valantin, M.A.; Simon, A.; Katlama, C.; Yeni, P.; Descamps, D.; Aubron-Olivier, C.; et al. Resistance profiles of emtricitabine and lamivudine in tenofovir-containing regimens. J. Antimicrob. Chemother. 2012, 67, 1475-1478. 
107. Ray, A.S.; Basavapathruni, A.; Anderson, K.S. Mechanistic studies to understand the progressive development of resistance in human immunodeficiency virus type 1 reverse transcriptase to abacavir. J. Biol. Chem. 2002, 277, 40479-40490.

108. Frangeul, A.; Bussetta, C.; Deval, J.; Barral, K.; Alvarez, K.; Canard, B. Gln151 of hiv-1 reverse transcriptase acts as a steric gate towards clinically relevant acyclic phosphonate nucleotide analogues. Antivir. Therapy 2008, 13, 115-124.

109. Mbisa, J.L.; Gupta, R.K.; Kabamba, D.; Mulenga, V.; Kalumbi, M.; Chintu, C.; Parry, C.M.; Gibb, D.M.; Walker, S.A.; Cane, P.A.; et al. The evolution of hiv-1 reverse transcriptase in route to acquisition of q151m multi-drug resistance is complex and involves mutations in multiple domains. Retrovirology 2011, 8, 31.

110. Hachiya, A.; Kodama, E.N.; Schuckmann, M.M.; Kirby, K.A.; Michailidis, E.; Sakagami, Y.; Oka, S.; Singh, K.; Sarafianos, S.G. K70q adds high-level tenofovir resistance to "q151m complex" hiv reverse transcriptase through the enhanced discrimination mechanism. PLoS One 2011, 6, e16242.

111. Kisic, M.; Mendieta, J.; Puertas, M.C.; Parera, M.; Martinez, M.A.; Martinez-Picado, J.; Menendez-Arias, L. Mechanistic basis of zidovudine hypersusceptibility and lamivudine resistance conferred by the deletion of codon 69 in the hiv-1 reverse transcriptase coding region. J. Mol. Biol. 2008, 382, 327-341.

112. Ding, J.; Das, K.; Hsiou, Y.; Sarafianos, S.G.; Clark, A.D., Jr.; Jacobo-Molina, A.; Tantillo, C.; Hughes, S.H.; Arnold, E. Structure and functional implications of the polymerase active site region in a complex of hiv-1 $\mathrm{rt}$ with a double-stranded DNA template-primer and an antibody fab fragment at 2.8 a resolution. J. Mol. Biol. 1998, 284, 1095-1111.

113. Lanier, E.R.; Givens, N.; Stone, C.; Griffin, P.; Gibb, D.; Walker, S.; Tisdale, M.; Irlbeck, D.; Underwood, M.; St Clair, M.; et al. Effect of concurrent zidovudine use on the resistance pathway selected by abacavir-containing regimens. HIV Med. 2004, 5, 394-399.

114. Waters, L.; Nelson, M.; Mandalia, S.; Bower, M.; Powles, T.; Gazzard, B.; Stebbing, J. The risks and incidence of $\mathrm{k} 65 \mathrm{r}$ and $174 \mathrm{v}$ mutations and subsequent virologic responses. Clin. Infect. Dis. 2008, 46, 96-100.

115. Miller, M.D.; Margot, N.; Lu, B.; Zhong, L.; Chen, S.S.; Cheng, A.; Wulfsohn, M. Genotypic and phenotypic predictors of the magnitude of response to tenofovir disoproxil fumarate treatment in antiretroviral-experienced patients. J. Infect. Dis. 2004, 189, 837-846.

116. Menendez-Arias, L. Molecular basis of human immunodeficiency virus drug resistance: An update. Antivir. Res. 2010, 85, 210-231.

117. Meyer, P.R.; Matsuura, S.E.; Tolun, A.A.; Pfeifer, I.; So, A.G.; Mellors, J.W.; Scott, W.A. Effects of specific zidovudine resistance mutations and substrate structure on nucleotidedependent primer unblocking by human immunodeficiency virus type 1 reverse transcriptase. Antimicrob. Agents Chemother. 2002, 46, 1540-1545.

118. Ray, A.S.; Murakami, E.; Basavapathruni, A.; Vaccaro, J.A.; Ulrich, D.; Chu, C.K.; Schinazi, R.F.; Anderson, K.S. Probing the molecular mechanisms of azt drug resistance mediated by hiv-1 reverse transcriptase using a transient kinetic analysis. Biochemistry 2003, 42, 8831-8841.

119. Menendez-Arias, L. Mechanisms of resistance to nucleoside analogue inhibitors of hiv-1 reverse transcriptase. Virus Res. 2008, 134, 124-146. 
120. Larder, B.A.; Coates, K.E.; Kemp, S.D. Zidovudine-resistant human immunodeficiency virus selected by passage in cell culture. J. Virol. 1991, 65, 5232-5236.

121. Hanna, G.J.; Johnson, V.A.; Kuritzkes, D.R.; Richman, D.D.; Brown, A.J.; Savara, A.V.; Hazelwood, J.D.; D’Aquila, R.T. Patterns of resistance mutations selected by treatment of human immunodeficiency virus type 1 infection with zidovudine, didanosine, and nevirapine. J. Infect. Dis. 2000, 181, 904-911.

122. Marcelin, A.G.; Delaugerre, C.; Wirden, M.; Viegas, P.; Simon, A.; Katlama, C.; Calvez, V. Thymidine analogue reverse transcriptase inhibitors resistance mutations profiles and association to other nucleoside reverse transcriptase inhibitors resistance mutations observed in the context of virological failure. J. Med. Virol. 2004, 72, 162-165.

123. Boyer, P.L.; Sarafianos, S.G.; Arnold, E.; Hughes, S.H. Selective excision of aztmp by drug-resistant human immunodeficiency virus reverse transcriptase. J. Virol. 2001, 75, 48324842.

124. Meyer, P.R.; Matsuura, S.E.; Schinazi, R.F.; So, A.G.; Scott, W.A. Differential removal of thymidine nucleotide analogues from blocked DNA chains by human immunodeficiency virus reverse transcriptase in the presence of physiological concentrations of 2'-deoxynucleoside triphosphates. Antimicrob. Agents Chemother. 2000, 44, 3465-3472.

125. Meyer, P.R.; Matsuura, S.E.; Mian, A.M.; So, A.G.; Scott, W.A. A mechanism of azt resistance: An increase in nucleotide-dependent primer unblocking by mutant hiv-1 reverse transcriptase. Mol. Cell 1999, 4, 35-43.

126. Tong, W.; Lu, C.D.; Sharma, S.K.; Matsuura, S.; So, A.G.; Scott, W.A. Nucleotide-induced stable complex formation by hiv-1 reverse transcriptase. Biochemistry 1997, 36, 5749-5757.

127. Marchand, B.; Gotte, M. Site-specific footprinting reveals differences in the translocation status of hiv-1 reverse transcriptase. Implications for polymerase translocation and drug resistance. $J$. Biol. Chem. 2003, 278, 35362-35372.

128. Marchand, B.; White, K.L.; Ly, J.K.; Margot, N.A.; Wang, R.; McDermott, M.; Miller, M.D.; Gotte, M. Effects of the translocation status of human immunodeficiency virus type 1 reverse transcriptase on the efficiency of excision of tenofovir. Antimicrob. Agents Chemother. 2007, 51, 2911-2919.

129. Iyidogan, P.; Anderson, K.S. Understanding the molecular mechanism of sequence dependent tenofovir removal by hiv-1 reverse transcriptase: Differences in primer binding site versus polypurine tract. Antivir. Res. 2012, 95, 93-103.

130. Tu, X.; Das, K.; Han, Q.; Bauman, J.D.; Clark, A.D., Jr.; Hou, X.; Frenkel, Y.V.; Gaffney, B.L.; Jones, R.A.; Boyer, P.L.; et al. Structural basis of hiv-1 resistance to azt by excision. Nat. Struct. Mol. Biol. 2010, 17, 1202-1209.

131. Dharmasena, S.; Pongracz, Z.; Arnold, E.; Sarafianos, S.G.; Parniak, M.A. 3'-azido-3'deoxythymidine-(5')-tetraphospho-(5')-adenosine, the product of atp-mediated excision of chain-terminating aztmp, is a potent chain-terminating substrate for hiv-1 reverse transcriptase. Biochemistry 2007, 46, 828-836.

132. Meyer, P.R.; Smith, A.J.; Matsuura, S.E.; Scott, W.A. Chain-terminating dinucleoside tetraphosphates are substrates for DNA polymerization by human immunodeficiency virus type 1 
reverse transcriptase with increased activity against thymidine analogue-resistant mutants. Antimicrob. Agents Chemother. 2006, 50, 3607-3614.

133. Eggink, D.; Huigen, M.C.; Boucher, C.A.; Gotte, M.; Nijhuis, M. Insertions in the beta3-beta4 loop of reverse transcriptase of human immunodeficiency virus type 1 and their mechanism of action, influence on drug susceptibility and viral replication capacity. Antivir. Res. 2007, 75, 93-103.

134. Cases-Gonzalez, C.E.; Franco, S.; Martinez, M.A.; Menendez-Arias, L. Mutational patterns associated with the 69 insertion complex in multi-drug-resistant hiv-1 reverse transcriptase that confer increased excision activity and high-level resistance to zidovudine. J. Mol. Biol. 2007, 365, 298-309.

135. Meyer, P.R.; Lennerstrand, J.; Matsuura, S.E.; Larder, B.A.; Scott, W.A. Effects of dipeptide insertions between codons 69 and 70 of human immunodeficiency virus type 1 reverse transcriptase on primer unblocking, deoxynucleoside triphosphate inhibition, and DNA chain elongation. J. Virol. 2003, 77, 3871-3877.

136. Boyer, P.L.; Sarafianos, S.G.; Arnold, E.; Hughes, S.H. Nucleoside analog resistance caused by insertions in the fingers of human immunodeficiency virus type 1 reverse transcriptase involves atp-mediated excision. J. Virol. 2002, 76, 9143-9151.

137. Kawamoto, A.; Kodama, E.; Sarafianos, S.G.; Sakagami, Y.; Kohgo, S.; Kitano, K.; Ashida, N.; Iwai, Y.; Hayakawa, H.; Nakata, H.; et al. 2'-deoxy-4'-c-ethynyl-2-halo-adenosines active against drug-resistant human immunodeficiency virus type 1 variants. Int. J. Biochem. Cell biol. 2008, 40, 2410-2420.

138. Kodama, E.I.; Kohgo, S.; Kitano, K.; Machida, H.; Gatanaga, H.; Shigeta, S.; Matsuoka, M.; Ohrui, H.; Mitsuya, H. 4'-ethynyl nucleoside analogs: Potent inhibitors of multidrug-resistant human immunodeficiency virus variants in vitro. Antimicrob. Agents Chemother. 2001, 45, 1539-1546.

139. Michailidis, E.; Marchand, B.; Kodama, E.N.; Singh, K.; Matsuoka, M.; Kirby, K.A.; Ryan, E.M.; Sawani, A.M.; Nagy, E.; Ashida, N.; et al. Mechanism of inhibition of hiv-1 reverse transcriptase by 4'-ethynyl-2-fluoro-2'-deoxyadenosine triphosphate, a translocation-defective reverse transcriptase inhibitor. J. Biol. Chem. 2009, 284, 35681-35691.

140. Nakata, H.; Amano, M.; Koh, Y.; Kodama, E.; Yang, G.; Bailey, C.M.; Kohgo, S.; Hayakawa, H.; Matsuoka, M.; Anderson, K.S.; et al. Activity against human immunodeficiency virus type 1, intracellular metabolism, and effects on human DNA polymerases of 4'-ethynyl-2-fluoro-2'deoxyadenosine. Antimicrob. Agents Chemother. 2007, 51, 2701-2708.

141. Ohrui, H.; Kohgo, S.; Hayakawa, H.; Kodama, E.; Matsuoka, M.; Nakata, T.; Mitsuya, H. 2'-deoxy-4'-c-ethynyl-2-fluoroadenosine: A nucleoside reverse transcriptase inhibitor with highly potent activity against wide spectrum of hiv-1 strains, favorable toxic profiles, and stability in plasma. Nucleosides Nucleotides Nucleic Acids 2007, 26, 1543-1546.

142. Sohl, C.D.; Singh, K.; Kasiviswanathan, R.; Copeland, W.C.; Mitsuya, H.; Sarafianos, S.G.; Anderson, K.S. Mechanism of interaction of human mitochondrial DNA polymerase gamma with the novel nucleoside reverse transcriptase inhibitor 4'-ethynyl-2-fluoro-2'-deoxyadenosine indicates a low potential for host toxicity. Antimicrob. Agents Chemother. 2012, 56, 1630-1634. 
143. Muftuoglu, Y.; Sohl, C.D.; Mislak, A.C.; Mitsuya, H.; Sarafianos, S.G.; Anderson, K.S. Probing the molecular mechanism of action of the hiv-1 reverse transcriptase inhibitor 4'-ethynyl-2fluoro-2'-deoxyadenosine (efda) using pre-steady-state kinetics. Antivir. Res. 2014, 106, 1-4.

144. Yang, G.; Dutschman, G.E.; Wang, C.J.; Tanaka, H.; Baba, M.; Anderson, K.S.; Cheng, Y.C. Highly selective action of triphosphate metabolite of 4'-ethynyl d4t: A novel anti-hiv compound against hiv-1 rt. Antivir. Res. 2007, 73, 185-191.

145. Dutschman, G.E.; Grill, S.P.; Gullen, E.A.; Haraguchi, K.; Takeda, S.; Tanaka, H.; Baba, M.; Cheng, Y.C. Novel 4'-substituted stavudine analog with improved anti-human immunodeficiency virus activity and decreased cytotoxicity. Antimicrob. Agents Chemother. 2004, 48, 1640-1646.

146. Li, Z.; Terry, B.; Olds, W.; Protack, T.; Deminie, C.; Minassian, B.; Nowicka-Sans, B.; Sun, Y.; Dicker, I.; Hwang, C.; et al. In vitro cross-resistance profile of nucleoside reverse transcriptase inhibitor (nrti) bms-986001 against known nrti resistance mutations. Antimicrob. Agents Chemother. 2013, 57, 5500-5508.

147. Yang, G.; Paintsil, E.; Dutschman, G.E.; Grill, S.P.; Wang, C.J.; Wang, J.; Tanaka, H.; Hamasaki, T.; Baba, M.; Cheng, Y.C. Impact of novel human immunodeficiency virus type 1 reverse transcriptase mutations p119s and t165a on 4'-ethynylthymidine analog resistance profile. Antimicrob. Agents Chemother. 2009, 53, 4640-4646.

148. Das, K.; Arnold, E. Hiv-1 reverse transcriptase and antiviral drug resistance. Part 1. Curr. Opin. Virol. 2013, 3, 111-118.

149. Spence, R.A.; Kati, W.M.; Anderson, K.S.; Johnson, K.A. Mechanism of inhibition of hiv-1 reverse transcriptase by nonnucleoside inhibitors. Science 1995, 267, 988-993.

150. Rittinger, K.; Divita, G.; Goody, R.S. Human immunodeficiency virus reverse transcriptase substrate-induced conformational changes and the mechanism of inhibition by nonnucleoside inhibitors. Proc. Natl. Acad. Sci. USA 1995, 92, 8046-8049.

151. Xia, Q.; Radzio, J.; Anderson, K.S.; Sluis-Cremer, N. Probing nonnucleoside inhibitor-induced active-site distortion in hiv-1 reverse transcriptase by transient kinetic analyses. Protein Sci. 2007, 16, 1728-1737.

152. Ren, J.; Milton, J.; Weaver, K.L.; Short, S.A.; Stuart, D.I.; Stammers, D.K. Structural basis for the resilience of efavirenz (dmp-266) to drug resistance mutations in hiv-1 reverse transcriptase. Struct. Fold Des. 2000, 8, 1089-1094.

153. Martins, S.; Ramos, M.J.; Fernandes, P.A. The current status of the nnrti family of antiretrovirals used in the haart regime against hiv infection. Curr. Med. Chem. 2008, 15, 1083-1095.

154. Hu, Z.; Kuritzkes, D.R. Altered viral fitness and drug susceptibility in human inmmunodeficiency virus type 1 (hiv-1) carrying mutations that confer resistance to non-nucleoside reverse transcriptase and integrase strand-transfer inhibitors. J. Virol. 2014, 88, 9268-9276.

155. Merluzzi, V.J.; Hargrave, K.D.; Labadia, M.; Grozinger, K.; Skoog, M.; Wu, J.C.; Shih, C.K.; Eckner, K.; Hattox, S.; Adams, J.; et al. Inhibition of hiv-1 replication by a nonnucleoside reverse transcriptase inhibitor. Science 1990, 250, 1411-1413.

156. Dueweke, T.J.; Poppe, S.M.; Romero, D.L.; Swaney, S.M.; So, A.G.; Downey, K.M.; Althaus, I.W.; Reusser, F.; Busso, M.; Resnick, L.; et al. U-90152, a potent inhibitor of human immunodeficiency virus type 1 replication. Antimicrob. Agents Chemother. 1993, 37, 11271131. 
157. Young, S.D.; Britcher, S.F.; Tran, L.O.; Payne, L.S.; Lumma, W.C.; Lyle, T.A.; Huff, J.R.; Anderson, P.S.; Olsen, D.B.; Carroll, S.S.; et al. L-743, 726 (dmp-266): A novel, highly potent nonnucleoside inhibitor of the human immunodeficiency virus type 1 reverse transcriptase. Antimicrob. Agents Chemother. 1995, 39, 2602-2605.

158. Andries, K.; Azijn, H.; Thielemans, T.; Ludovici, D.; Kukla, M.; Heeres, J.; Janssen, P.; de Corte, B.; Vingerhoets, J.; Pauwels, R.; et al. Tmc125, a novel next-generation nonnucleoside reverse transcriptase inhibitor active against nonnucleoside reverse transcriptase inhibitorresistant human immunodeficiency virus type 1. Antimicrob. Agents Chemother. 2004, 48, 4680-4686.

159. Janssen, P.A.; Lewi, P.J.; Arnold, E.; Daeyaert, F.; de Jonge, M.; Heeres, J.; Koymans, L.; Vinkers, M.; Guillemont, J.; Pasquier, E.; et al. In search of a novel anti-hiv drug: Multidisciplinary coordination in the discovery of 4-[[4-[[4-[(1e)-2-cyanoethenyl]-2,6dimethylphenyl]amino]-2- pyrimidinyl]amino]benzonitrile (r278474, rilpivirine). J. Med. Chem. 2005, 48, 1901-1909.

160. Soriano, V.; de Mendoza, C. Genetic mechanisms of resistance to nrti and nnrti. HIV Clin. Trials 2002, 3, 237-248.

161. Kohlstaedt, L.A.; Wang, J.; Friedman, J.M.; Rice, P.A.; Steitz, T.A. Crystal structure at 3.5 a resolution of hiv-1 reverse transcriptase complexed with an inhibitor. Science 1992, 256, 1783-1790.

162. Esnouf, R.; Ren, J.; Ross, C.; Jones, Y.; Stammers, D.; Stuart, D. Mechanism of inhibition of hiv-1 reverse transcriptase by non-nucleoside inhibitors. Nat. Struct. Biol. 1995, 2, 303-308.

163. Department of Health and Human Services. Guidelines for the Use of Antiretroviral Agents in HIV-1-Infected Adults and Adolescents; Office of Aids Research Advisory Council: Bethesda, USA, 2011; pp. 1-174.

164. Deparment of Health and Human Services - A working group of the office of AIDS research advisory council. Guidelines for the Use of Antiretroviral Agents in HIV-1-Infected Adults and Adolescents; 2014; pp. 1-284. Available online: http://aidsinfo.nih.gov/ContentFiles/AdultandAdolescentGL.pdf (accessed on 15 October 2014)

165. Tambuyzer, L.; Azijn, H.; Rimsky, L.T.; Vingerhoets, J.; Lecocq, P.; Kraus, G.; Picchio, G.; de Bethune, M.P. Compilation and prevalence of mutations associated with resistance to non-nucleoside reverse transcriptase inhibitors. Antivir. Therapy 2009, 14, 103-109.

166. Hsiou, Y.; Ding, J.; Das, K.; Clark, A.D., Jr.; Boyer, P.L.; Lewi, P.; Janssen, P.A.; Kleim, J.P.; Rosner, M.; Hughes, S.H.; et al. The lys103asn mutation of hiv-1 rt: A novel mechanism of drug resistance. J. Mol. Biol. 2001, 309, 437-445.

167. Lindberg, J.; Sigurdsson, S.; Lowgren, S.; Andersson, H.O.; Sahlberg, C.; Noreen, R.; Fridborg, K.; Zhang, H.; Unge, T. Structural basis for the inhibitory efficacy of efavirenz (dmp-266), msc194 and pnu142721 towards the hiv-1 rt k103n mutant. Eur. J. Biochem./FEBS 2002, 269, 1670-1677.

168. Harrigan, P.R.; Mo, T.; Wynhoven, B.; Hirsch, J.; Brumme, Z.; McKenna, P.; Pattery, T.; Vingerhoets, J.; Bacheler, L.T. Rare mutations at codon 103 of hiv-1 reverse transcriptase can confer resistance to non-nucleoside reverse transcriptase inhibitors. AIDS 2005, 19, 549-554. 
169. Parkin, N.T.; Gupta, S.; Chappey, C.; Petropoulos, C.J. The k101p and k103r/v179d mutations in human immunodeficiency virus type 1 reverse transcriptase confer resistance to nonnucleoside reverse transcriptase inhibitors. Antimicrob. Agents Chemother. 2006, 50, 351-354.

170. Ren, J.; Esnouf, R.; Garman, E.; Somers, D.; Ross, C.; Kirby, I.; Keeling, J.; Darby, G.; Jones, Y.; Stuart, D.; et al. High resolution structures of hiv-1 rt from four rt-inhibitor complexes. Nat. Struct. Biol. 1995, 2, 293-302.

171. De Clercq, E. Non-nucleoside reverse transcriptase inhibitors (nnrtis): Past, present, and future. Chem. Biodivers. 2004, 1, 44-64.

172. Petropoulos, C.J.; Parkin, N.T.; Limoli, K.L.; Lie, Y.S.; Wrin, T.; Huang, W.; Tian, H.; Smith, D.; Winslow, G.A.; Capon, D.J.; et al. A novel phenotypic drug susceptibility assay for human immunodeficiency virus type 1. Antimicrob. Agents Chemother. 2000, 44, 920-928.

173. Walmsley, S.L.; Kelly, D.V.; Tseng, A.L.; Humar, A.; Harrigan, P.R. Non-nucleoside reverse transcriptase inhibitor failure impairs hiv-rna responses to efavirenz-containing salvage antiretroviral therapy. AIDS 2001, 15, 1581-1584.

174. Delaugerre, C.; Rohban, R.; Simon, A.; Mouroux, M.; Tricot, C.; Agher, R.; Huraux, J.M.; Katlama, C.; Calvez, V. Resistance profile and cross-resistance of hiv-1 among patients failing a non-nucleoside reverse transcriptase inhibitor-containing regimen. J. Med. Virol. 2001, 65, 445-448.

175. Bacheler, L.; Jeffrey, S.; Hanna, G.; D’Aquila, R.; Wallace, L.; Logue, K.; Cordova, B.; Hertogs, K.; Larder, B.; Buckery, R.; et al. Genotypic correlates of phenotypic resistance to efavirenz in virus isolates from patients failing nonnucleoside reverse transcriptase inhibitor therapy. J. Virol. 2001, 75, 4999-5008.

176. Huang, W.; Gamarnik, A.; Limoli, K.; Petropoulos, C.J.; Whitcomb, J.M. Amino acid substitutions at position 190 of human immunodeficiency virus type 1 reverse transcriptase increase susceptibility to delavirdine and impair virus replication. J. Virol. 2003, 77, 1512-1523.

177. Kleim, J.P.; Bender, R.; Kirsch, R.; Meichsner, C.; Paessens, A.; Riess, G. Mutational analysis of residue 190 of human immunodeficiency virus type 1 reverse transcriptase. Virology 1994, 200, 696-701.

178. Ludovici, D.W.; de Corte, B.L.; Kukla, M.J.; Ye, H.; Ho, C.Y.; Lichtenstein, M.A.; Kavash, R.W.; Andries, K.; de Bethune, M.P.; Azijn, H.; et al. Evolution of anti-hiv drug candidates. Part 3: Diarylpyrimidine (dapy) analogues. Bioorganic Med. Chem. Lett. 2001, 11, 2235-2239.

179. Vingerhoets, J.; Azijn, H.; Fransen, E.; de Baere, I.; Smeulders, L.; Jochmans, D.; Andries, K.; Pauwels, R.; de Bethune, M.P. Tmc125 displays a high genetic barrier to the development of resistance: Evidence from in vitro selection experiments. J. Virol. 2005, 79, 12773-12782.

180. Das, K.; Clark, A.D., Jr.; Lewi, P.J.; Heeres, J.; de Jonge, M.R.; Koymans, L.M.; Vinkers, H.M.; Daeyaert, F.; Ludovici, D.W.; Kukla, M.J.; et al. Roles of conformational and positional adaptability in structure-based design of tmc125-r165335 (etravirine) and related non-nucleoside reverse transcriptase inhibitors that are highly potent and effective against wild-type and drugresistant hiv-1 variants. J. Med. Chem. 2004, 47, 2550-2560.

181. Das, K.; Bauman, J.D.; Clark, A.D., Jr.; Frenkel, Y.V.; Lewi, P.J.; Shatkin, A.J.; Hughes, S.H.; Arnold, E. High-resolution structures of hiv-1 reverse transcriptase/tmc278 complexes: Strategic 
flexibility explains potency against resistance mutations. Proc. Natl. Acad. Sci. USA 2008, 105, 1466-1471.

182. Lansdon, E.B.; Brendza, K.M.; Hung, M.; Wang, R.; Mukund, S.; Jin, D.; Birkus, G.; Kutty, N.; Liu, X. Crystal structures of hiv-1 reverse transcriptase with etravirine (tmc125) and rilpivirine (tmc278): Implications for drug design. J. Med. Chem. 2010, 53, 4295-4299.

183. Xu, H.T.; Quan, Y.; Schader, S.M.; Oliveira, M.; Bar-Magen, T.; Wainberg, M.A. The m2301 nonnucleoside reverse transcriptase inhibitor resistance mutation in hiv-1 reverse transcriptase impairs enzymatic function and viral replicative capacity. Antimicrob. Agents Chemother. 2010, 54, 2401-2408.

184. Madruga, J.V.; Cahn, P.; Grinsztejn, B.; Haubrich, R.; Lalezari, J.; Mills, A.; Pialoux, G.; Wilkin, T.; Peeters, M.; Vingerhoets, J.; et al. Efficacy and safety of tmc125 (etravirine) in treatmentexperienced hiv-1-infected patients in duet-1: 24-week results from a randomised, double-blind, placebo-controlled trial. Lancet 2007, 370, 29-38.

185. Lazzarin, A.; Campbell, T.; Clotet, B.; Johnson, M.; Katlama, C.; Moll, A.; Towner, W.; Trottier, B.; Peeters, M.; Vingerhoets, J.; et al. Efficacy and safety of tmc125 (etravirine) in treatmentexperienced hiv-1-infected patients in duet-2: 24-week results from a randomised, double-blind, placebo-controlled trial. Lancet 2007, 370, 39-48.

186. Vingerhoets, J.; Tambuyzer, L.; Azijn, H.; Hoogstoel, A.; Nijs, S.; Peeters, M.; de Bethune, M.P.; de Smedt, G.; Woodfall, B.; Picchio, G. Resistance profile of etravirine: Combined analysis of baseline genotypic and phenotypic data from the randomized, controlled phase iii clinical studies. AIDS 2010, 24, 503-514.

187. Towner, W.J.; Cassetti, I.; Domingo, P.; Nijs, S.; Kakuda, T.N.; Vingerhoets, J.; Woodfall, B. Etravirine: Clinical review of a treatment option for hiv type-1-infected patients with non-nucleoside reverse transcriptase inhibitor resistance. Antivir. Therapy 2010, 15, 803-816.

188. Marcelin, A.G.; Flandre, P.; Descamps, D.; Morand-Joubert, L.; Charpentier, C.; Izopet, J.; Trabaud, M.A.; Saoudin, H.; Delaugerre, C.; Tamalet, C.; et al. Factors associated with virological response to etravirine in nonnucleoside reverse transcriptase inhibitor-experienced hiv-1-infected patients. Antimicrob. Agents Chemother. 2010, 54, 72-77.

189. Xu, H.T.; Colby-Germinario, S.P.; Asahchop, E.L.; Oliveira, M.; McCallum, M.; Schader, S.M.; Han, Y.; Quan, Y.; Sarafianos, S.G.; Wainberg, M.A. Effect of mutations at position e138 in hiv-1 reverse transcriptase and their interactions with the m184i mutation on defining patterns of resistance to nonnucleoside reverse transcriptase inhibitors rilpivirine and etravirine. Antimicrob. Agents Chemother. 2013, 57, 3100-3109.

190. Xu, H.T.; Oliveira, M.; Asahchop, E.L.; McCallum, M.; Quashie, P.K.; Han, Y.; Quan, Y.; Wainberg, M.A. Molecular mechanism of antagonism between the y181c and e138k mutations in hiv-1 reverse transcriptase. J. Virol. 2012, 86, 12983-12990.

191. Poveda, E.; de Mendoza, C.; Pattery, T.; Gonzalez Mdel, M.; Villacian, J.; Soriano, V. Phenotypic impact of resistance mutations on etravirine susceptibility in hiv patients with prior failure to nonnucleoside analogues. AIDS 2008, 22, 2395-2398.

192. Gupta, S.; Vingerhoets, J.; Fransen, S.; Tambuyzer, L.; Azijn, H.; Frantzell, A.; Paredes, R.; Coakley, E.; Nijs, S.; Clotet, B.; et al. Connection domain mutations in hiv-1 reverse 
transcriptase do not impact etravirine susceptibility and virologic responses to etravirinecontaining regimens. Antimicrob. Agents Chemother. 2011, 55, 2872-2879.

193. Xu, H.T.; Colby-Germinario, S.P.; Oliveira, M.; Han, Y.; Quan, Y.; Zanichelli, V.; Wainberg, M.A. The connection domain mutation $\mathrm{n} 348 \mathrm{i}$ in hiv-1 reverse transcriptase enhances resistance to etravirine and rilpivirine but restricts the emergence of the e138k resistance mutation by diminishing viral replication capacity. J. Virol. 2014, 88, 1536-1547.

194. Sharma, M.; Saravolatz, L.D. Rilpivirine: A new non-nucleoside reverse transcriptase inhibitor. J. Antimicrob. Chemother. 2013, 68, 250-256.

195. Johnson, B.C.; Pauly, G.T.; Rai, G.; Patel, D.; Bauman, J.D.; Baker, H.L.; Das, K.; Schneider, J.P.; Maloney, D.J.; Arnold, E.; et al. A comparison of the ability of rilpivirine (tmc278) and selected analogues to inhibit clinically relevant hiv-1 reverse transcriptase mutants. Retrovirology 2012, 9, 99.

196. Asahchop, E.L.; Wainberg, M.A.; Oliveira, M.; Xu, H.; Brenner, B.G.; Moisi, D.; Ibanescu, I.R.; Tremblay, C. Distinct resistance patterns to etravirine and rilpivirine in viruses containing nonnucleoside reverse transcriptase inhibitor mutations at baseline. AIDS 2013, 27, 879-887.

197. Xu, H.T.; Colby-Germinario, S.P.; Huang, W.; Oliveira, M.; Han, Y.; Quan, Y.; Petropoulos, C.J.; Wainberg, M.A. Role of the k101e substitution in hiv-1 reverse transcriptase in resistance to rilpivirine and other nonnucleoside reverse transcriptase inhibitors. Antimicrob. Agents Chemother. 2013, 57, 5649-5657.

198. Singh, K.; Marchand, B.; Rai, D.K.; Sharma, B.; Michailidis, E.; Ryan, E.M.; Matzek, K.B.; Leslie, M.D.; Hagedorn, A.N.; Li, Z.; et al. Biochemical mechanism of hiv-1 resistance to rilpivirine. J. Biol. Chem. 2012, 287, 38110-38123.

199. Rimsky, L.; Van Eygen, V.; Hoogstoel, A.; Stevens, M.; Boven, K.; Picchio, G.; Vingerhoets, J. 96-week resistance analyses of rilpivirine in treatment-naive, hiv-1-infected adults from the echo and thrive phase iii trials. Antivir. Therapy 2013, 18, 967-977.

200. Kohl, N.E.; Emini, E.A.; Schleif, W.A.; Davis, L.J.; Heimbach, J.C.; Dixon, R.A.; Scolnick, E.M.; Sigal, I.S. Active human immunodeficiency virus protease is required for viral infectivity. Proc. Natl. Acad. Sci. USA 1988, 85, 4686-4690.

201. Roberts, N.A.; Martin, J.A.; Kinchington, D.; Broadhurst, A.V.; Craig, J.C.; Duncan, I.B.; Galpin, S.A.; Handa, B.K.; Kay, J.; Krohn, A.; et al. Rational design of peptide-based hiv proteinase inhibitors. Science 1990, 248, 358-361.

202. Huff, J.R.; Kahn, J. Discovery and clinical development of hiv-1 protease inhibitors. Adv. Protein Chem. 2001, 56, 213-251.

203. Louis, J.M.; Ishima, R.; Torchia, D.A.; Weber, I.T. Hiv-1 protease: Structure, dynamics, and inhibition. Adv. Pharmacol. 2007, 55, 261-298.

204. Hull, M.W.; Montaner, J.S. Ritonavir-boosted protease inhibitors in hiv therapy. Ann. Med. 2011, 43, 375-388.

205. Kempf, D.J.; Marsh, K.C.; Kumar, G.; Rodrigues, A.D.; Denissen, J.F.; McDonald, E.; Kukulka, M.J.; Hsu, A.; Granneman, G.R.; Baroldi, P.A.; et al. Pharmacokinetic enhancement of inhibitors of the human immunodeficiency virus protease by coadministration with ritonavir. Antimicrob. Agents Chemother. 1997, 41, 654-660. 
206. Stanford HIV Drug Resistance Database. Major HIV-1 drug resistance mutations. Available online: http://hivdb.Stanford.edu (accessed on 16 June 2014).

207. Swain, A.L.; Miller, M.M.; Green, J.; Rich, D.H.; Schneider, J.; Kent, S.B.; Wlodawer, A. X-ray crystallographic structure of a complex between a synthetic protease of human immunodeficiency virus 1 and a substrate-based hydroxyethylamine inhibitor. Proc. Natl. Acad. Sci. USA 1990, 87, 8805-8809.

208. Gulnik, S.V.; Suvorov, L.I.; Liu, B.; Yu, B.; Anderson, B.; Mitsuya, H.; Erickson, J.W. Kinetic characterization and cross-resistance patterns of hiv-1 protease mutants selected under drug pressure. Biochemistry 1995, 34, 9282-9287.

209. Johnson, V.A.; Calvez, V.; Gunthard, H.F.; Paredes, R.; Pillay, D.; Shafer, R.; Wensing, A.M.; Richman, D.D. 2011 update of the drug resistance mutations in hiv-1. Top. Antivir. Med. 2011, 19, 156-164.

210. Markowitz, M.; Conant, M.; Hurley, A.; Schluger, R.; Duran, M.; Peterkin, J.; Chapman, S.; Patick, A.; Hendricks, A.; Yuen, G.J.; et al. A preliminary evaluation of nelfinavir mesylate, an inhibitor of human immunodeficiency virus (hiv)-1 protease, to treat hiv infection. J. Infect. Dis. 1998, 177, 1533-1540.

211. Rhee, S.Y.; Taylor, J.; Fessel, W.J.; Kaufman, D.; Towner, W.; Troia, P.; Ruane, P.; Hellinger, J.; Shirvani, V.; Zolopa, A.; et al. Hiv-1 protease mutations and protease inhibitor crossresistance. Antimicrob. Agents Chemother. 2010, 54, 4253-4261.

212. Mahalingam, B.; Louis, J.M.; Reed, C.C.; Adomat, J.M.; Krouse, J.; Wang, Y.F.; Harrison, R.W.; Weber, I.T. Structural and kinetic analysis of drug resistant mutants of hiv-1 protease. Eur. J. Biochem./FEBS 1999, 263, 238-245.

213. Prabu-Jeyabalan, M.; Nalivaika, E.; Schiffer, C.A. Substrate shape determines specificity of recognition for hiv-1 protease: Analysis of crystal structures of six substrate complexes. Structure 2002, 10, 369-381.

214. King, N.M.; Prabu-Jeyabalan, M.; Nalivaika, E.A.; Schiffer, C.A. Combating susceptibility to drug resistance: Lessons from hiv-1 protease. Chem. Biol. 2004, 11, 1333-1338.

215. King, N.M.; Melnick, L.; Prabu-Jeyabalan, M.; Nalivaika, E.A.; Yang, S.S.; Gao, Y.; Nie, X.; Zepp, C.; Heefner, D.L.; Schiffer, C.A. Lack of synergy for inhibitors targeting a multi-drug-resistant hiv-1 protease. Protein Sci. 2002, 11, 418-429.

216. Munshi, S.; Chen, Z.; Yan, Y.; Li, Y.; Olsen, D.B.; Schock, H.B.; Galvin, B.B.; Dorsey, B.; Kuo, L.C. An alternate binding site for the p1-p3 group of a class of potent hiv-1 protease inhibitors as a result of concerted structural change in the 80 s loop of the protease. Acta Crystallogr. Sect. D Biol. Crystallogr. 2000, 56, 381-388.

217. Johnson, V.A.; Calvez, V.; Gunthard, H.F.; Paredes, R.; Pillay, D.; Shafer, R.W.; Wensing, A.M.; Richman, D.D. Update of the drug resistance mutations in hiv-1: March 2013. Top. Antivir. Med. 2013, 21, 6-14.

218. Kaldor, S.W.; Kalish, V.J.; Davies, J.F., 2nd; Shetty, B.V.; Fritz, J.E.; Appelt, K.; Burgess, J.A.; Campanale, K.M.; Chirgadze, N.Y.; Clawson, D.K.; et al. Viracept (nelfinavir mesylate, ag1343): A potent, orally bioavailable inhibitor of hiv-1 protease. J. Med. Chem. 1997, 40, 39793985. 
219. Sugiura, W.; Matsuda, Z.; Yokomaku, Y.; Hertogs, K.; Larder, B.; Oishi, T.; Okano, A.; Shiino, T.; Tatsumi, M.; Matsuda, M.; et al. Interference between d30n and 190m in selection and development of protease inhibitor-resistant human immunodeficiency virus type 1. Antimicrob. Agents Chemother. 2002, 46, 708-715.

220. Menendez-Arias, L.; Martinez, M.A.; Quinones-Mateu, M.E.; Martinez-Picado, J. Fitness variations and their impact on the evolution of antiretroviral drug resistance. Curr. Drug Targets 2003, 3, 355-371.

221. Chang, M.W.; Torbett, B.E. Accessory mutations maintain stability in drug-resistant hiv-1 protease. J. Mol. Biol. 2011, 410, 756-760.

222. Zhang, Y.M.; Imamichi, H.; Imamichi, T.; Lane, H.C.; Falloon, J.; Vasudevachari, M.B.; Salzman, N.P. Drug resistance during indinavir therapy is caused by mutations in the protease gene and in its gag substrate cleavage sites. J. Virol. 1997, 71, 6662-6670.

223. Doyon, L.; Croteau, G.; Thibeault, D.; Poulin, F.; Pilote, L.; Lamarre, D. Second locus involved in human immunodeficiency virus type 1 resistance to protease inhibitors. J. Virol. 1996, 70, 3763-3769.

224. Robinson, L.H.; Myers, R.E.; Snowden, B.W.; Tisdale, M.; Blair, E.D. Hiv type 1 protease cleavage site mutations and viral fitness: Implications for drug susceptibility phenotyping assays. AIDS Res. Hum. Retrovir. 2000, 16, 1149-1156.

225. Pettit, S.C.; Henderson, G.J.; Schiffer, C.A.; Swanstrom, R. Replacement of the p1 amino acid of human immunodeficiency virus type 1 gag processing sites can inhibit or enhance the rate of cleavage by the viral protease. J. Virol. 2002, 76, 10226-10233.

226. Feher, A.; Weber, I.T.; Bagossi, P.; Boross, P.; Mahalingam, B.; Louis, J.M.; Copeland, T.D.; Torshin, I.Y.; Harrison, R.W.; Tozser, J. Effect of sequence polymorphism and drug resistance on two hiv-1 gag processing sites. Eur. J. Biochem./FEBS 2002, 269, 4114-4120.

227. Doyon, L.; Payant, C.; Brakier-Gingras, L.; Lamarre, D. Novel gag-pol frameshift site in human immunodeficiency virus type 1 variants resistant to protease inhibitors. J. Virol. 1998, 72, 6146-6150.

228. Gatanaga, H.; Suzuki, Y.; Tsang, H.; Yoshimura, K.; Kavlick, M.F.; Nagashima, K.; Gorelick, R.J.; Mardy, S.; Tang, C.; Summers, M.F.; et al. Amino acid substitutions in gag protein at noncleavage sites are indispensable for the development of a high multitude of hiv-1 resistance against protease inhibitors. J. Biol. Chem. 2002, 277, 5952-5961.

229. Dam, E.; Quercia, R.; Glass, B.; Descamps, D.; Launay, O.; Duval, X.; Krausslich, H.G.; Hance, A.J.; Clavel, F.; Group, A.S. Gag mutations strongly contribute to hiv-1 resistance to protease inhibitors in highly drug-experienced patients besides compensating for fitness loss. PLoS Pathog. 2009, 5, e1000345.

230. Myint, L.; Matsuda, M.; Matsuda, Z.; Yokomaku, Y.; Chiba, T.; Okano, A.; Yamada, K.; Sugiura, W. Gag non-cleavage site mutations contribute to full recovery of viral fitness in protease inhibitor-resistant human immunodeficiency virus type 1. Antimicrob. Agents Chemother. 2004, 48, 444-452.

231. Grant, P.; Wong, E.C.; Rode, R.; Shafer, R.; de Luca, A.; Nadler, J.; Hawkins, T.; Cohen, C.; Harrington, R.; Kempf, D.; et al. Virologic response to lopinavir-ritonavir-based antiretroviral 
regimens in a multicenter international clinical cohort: Comparison of genotypic interpretation scores. Antimicrob. Agents Chemother. 2008, 52, 4050-4056.

232. Becker, S.; Thornton, L. Fosamprenavir: Advancing hiv protease inhibitor treatment options. Expert Opin. Pharmacother. 2004, 5, 1995-2005.

233. Marcelin, A.G.; Masquelier, B.; Descamps, D.; Izopet, J.; Charpentier, C.; Alloui, C.; Bouvier-Alias, M.; Signori-Schmuck, A.; Montes, B.; Chaix, M.L.; et al. Tipranavir-ritonavir genotypic resistance score in protease inhibitor-experienced patients. Antimicrob. Agents Chemother. 2008, 52, 3237-3243.

234. De Meyer, S.; Hill, A.; Picchio, G.; DeMasi, R.; de Paepe, E.; de Bethune, M.P. Influence of baseline protease inhibitor resistance on the efficacy of darunavir/ritonavir or lopinavir/ritonavir in the titan trial. J. Acquir. Immune Defic. Syndr. 2008, 49, 563-564.

235. Ali, A.; Bandaranayake, R.M.; Cai, Y.; King, N.M.; Kolli, M.; Mittal, S.; Murzycki, J.F.; Nalam, M.N.; Nalivaika, E.A.; Ozen, A.; et al. Molecular basis for drug resistance in hiv-1 protease. Viruses 2010, 2, 2509-2535.

236. Ghosh, A.K.; Parham, G.L.; Martyr, C.D.; Nyalapatla, P.R.; Osswald, H.L.; Agniswamy, J.; Wang, Y.F.; Amano, M.; Weber, I.T.; Mitsuya, H. Highly potent hiv-1 protease inhibitors with novel tricyclic p2 ligands: Design, synthesis, and protein-ligand x-ray studies. J. Med. Chem. 2013, 56, 6792-6802.

237. Chow, S.A.; Vincent, K.A.; Ellison, V.; Brown, P.O. Reversal of integration and DNA splicing mediated by integrase of human immunodeficiency virus. Science 1992, 255, 723-726.

238. Engelman, A.; Bushman, F.D.; Craigie, R. Identification of discrete functional domains of hiv-1 integrase and their organization within an active multimeric complex. EMBO J. 1993, 12, 3269-3275.

239. Hazuda, D.J.; Felock, P.; Witmer, M.; Wolfe, A.; Stillmock, K.; Grobler, J.A.; Espeseth, A.; Gabryelski, L.; Schleif, W.; Blau, C.; et al. Inhibitors of strand transfer that prevent integration and inhibit hiv-1 replication in cells. Science 2000, 287, 646-650.

240. Delelis, O.; Carayon, K.; Saib, A.; Deprez, E.; Mouscadet, J.F. Integrase and integration: Biochemical activities of hiv-1 integrase. Retrovirology 2008, 5, 114.

241. Craigie, R. The molecular biology of hiv integrase. Future Virol. 2012, 7, 679-686.

242. Metifiot, M.; Marchand, C.; Pommier, Y. Hiv integrase inhibitors: 20-year landmark and challenges. Adv. Pharmacol. 2013, 67, 75-105.

243. Hazuda, D.J.; Felock, P.J.; Hastings, J.C.; Pramanik, B.; Wolfe, A.L. Differential divalent cation requirements uncouple the assembly and catalytic reactions of human immunodeficiency virus type 1 integrase. J. Virol. 1997, 71, 7005-7011.

244. Hicks, C.; Gulick, R.M. Raltegravir: The first hiv type 1 integrase inhibitor. Clin. Infect. Dis. 2009, 48, 931-939.

245. Cooper, D.A.; Steigbigel, R.T.; Gatell, J.M.; Rockstroh, J.K.; Katlama, C.; Yeni, P.; Lazzarin, A.; Clotet, B.; Kumar, P.N.; Eron, J.E.; et al. Subgroup and resistance analyses of raltegravir for resistant hiv-1 infection. N. Engl. J. Med. 2008, 359, 355-365.

246. Canducci, F.; Sampaolo, M.; Marinozzi, M.C.; Boeri, E.; Spagnuolo, V.; Galli, A.; Castagna, A.; Lazzarin, A.; Clementi, M.; Gianotti, N. Dynamic patterns of human immunodeficiency virus 
type 1 integrase gene evolution in patients failing raltegravir-based salvage therapies. AIDS 2009, $23,455-460$.

247. Hurt, C.B.; Sebastian, J.; Hicks, C.B.; Eron, J.J. Resistance to hiv integrase strand transfer inhibitors among clinical specimens in the united states, 2009-2012. Clin. Infect. Dis. 2014, 58, 423-431.

248. Malet, I.; Delelis, O.; Valantin, M.A.; Montes, B.; Soulie, C.; Wirden, M.; Tchertanov, L.; Peytavin, G.; Reynes, J.; Mouscadet, J.F.; et al. Mutations associated with failure of raltegravir treatment affect integrase sensitivity to the inhibitor in vitro. Antimicrob. Agents Chemother. 2008, 52, 1351-1358.

249. Nakahara, K.; Wakasa-Morimoto, C.; Kobayashi, M.; Miki, S.; Noshi, T.; Seki, T.; Kanamori-Koyama, M.; Kawauchi, S.; Suyama, A.; Fujishita, T.; et al. Secondary mutations in viruses resistant to hiv-1 integrase inhibitors that restore viral infectivity and replication kinetics. Antivir. Res. 2009, 81, 141-146.

250. Delelis, O.; Malet, I.; Na, L.; Tchertanov, L.; Calvez, V.; Marcelin, A.G.; Subra, F.; Deprez, E.; Mouscadet, J.F. The g140s mutation in hiv integrases from raltegravir-resistant patients rescues catalytic defect due to the resistance q148h mutation. Nucleic Acids Res. 2009, 37, 1193-1201.

251. Marchand, C. The elvitegravir quad pill: The first once-daily dual-target anti-hiv tablet. Expert Opin. Investig. Drugs 2012, 21, 901-904.

252. Blanco, J.L.; Varghese, V.; Rhee, S.Y.; Gatell, J.M.; Shafer, R.W. Hiv-1 integrase inhibitor resistance and its clinical implications. J. Infect. Dis. 2011, 203, 1204-1214.

253. Goethals, O.; Clayton, R.; van Ginderen, M.; Vereycken, I.; Wagemans, E.; Geluykens, P.; Dockx, K.; Strijbos, R.; Smits, V.; Vos, A.; et al. Resistance mutations in human immunodeficiency virus type 1 integrase selected with elvitegravir confer reduced susceptibility to a wide range of integrase inhibitors. J. Virol. 2008, 82, 10366-10374.

254. Shimura, K.; Kodama, E.; Sakagami, Y.; Matsuzaki, Y.; Watanabe, W.; Yamataka, K.; Watanabe, Y.; Ohata, Y.; Doi, S.; Sato, M.; et al. Broad antiretroviral activity and resistance profile of the novel human immunodeficiency virus integrase inhibitor elvitegravir (jtk-303/gs-9137). J. Virol. 2008, 82, 764-774.

255. Kobayashi, M.; Yoshinaga, T.; Seki, T.; Wakasa-Morimoto, C.; Brown, K.W.; Ferris, R.; Foster, S.A.; Hazen, R.J.; Miki, S.; Suyama-Kagitani, A.; et al. In vitro antiretroviral properties of s/gsk1349572, a next-generation hiv integrase inhibitor. Antimicrob. Agents Chemother. 2011, $55,813-821$.

256. Hightower, K.E.; Wang, R.; Deanda, F.; Johns, B.A.; Weaver, K.; Shen, Y.; Tomberlin, G.H.; Carter, H.L., 3rd; Broderick, T.; Sigethy, S.; et al. Dolutegravir (s/gsk1349572) exhibits significantly slower dissociation than raltegravir and elvitegravir from wild-type and integrase inhibitor-resistant hiv-1 integrase-DNA complexes. Antimicrob. Agents Chemother. 2011, 55, 4552-4559.

257. Eron, J.J.; Clotet, B.; Durant, J.; Katlama, C.; Kumar, P.; Lazzarin, A.; Poizot-Martin, I.; Richmond, G.; Soriano, V.; Ait-Khaled, M.; et al. Safety and efficacy of dolutegravir in treatment-experienced subjects with raltegravir-resistant hiv type 1 infection: 24-week results of the viking study. J. Infect. Dis. 2013, 207, 740-748.

258. Quashie, P.K.; Mesplede, T.; Han, Y.S.; Oliveira, M.; Singhroy, D.N.; Fujiwara, T.; Underwood, M.R.; Wainberg, M.A. Characterization of the r263k mutation in hiv-1 integrase that confers 
low-level resistance to the second-generation integrase strand transfer inhibitor dolutegravir. $J$. Virol. 2012, 86, 2696-2705.

259. Cahn, P.; Pozniak, A.L.; Mingrone, H.; Shuldyakov, A.; Brites, C.; Andrade-Villanueva, J.F.; Richmond, G.; Buendia, C.B.; Fourie, J.; Ramgopal, M.; et al. Dolutegravir versus raltegravir in antiretroviral-experienced, integrase-inhibitor-naive adults with hiv: Week 48 results from the randomised, double-blind, non-inferiority sailing study. Lancet 2013, 382, 700-708.

260. Mesplede, T.; Quashie, P.K.; Osman, N.; Han, Y.; Singhroy, D.N.; Lie, Y.; Petropoulos, C.J.; Huang, W.; Wainberg, M.A. Viral fitness cost prevents hiv-1 from evading dolutegravir drug pressure. Retrovirology 2013, 10, 22.

261. Quashie, P.K.; Mesplede, T.; Han, Y.S.; Veres, T.; Osman, N.; Hassounah, S.; Sloan, R.D.; $\mathrm{Xu}$, H.T.; Wainberg, M.A. Biochemical analysis of the role of g118r-linked dolutegravir drug resistance substitutions in hiv-1 integrase. Antimicrob. Agents Chemother. 2014, 58, 3580.

262. Oliveira, M.; Mesplede, T.; Quashie, P.K.; Moisi, D.; Wainberg, M.A. Resistance mutations against dolutegravir in hiv integrase impair the emergence of resistance against reverse transcriptase inhibitors. AIDS 2014, 28, 813-819.

263. Haqqani, A.A.; Tilton, J.C. Entry inhibitors and their use in the treatment of hiv-1 infection. Antivir. Res. 2013, 98, 158-170.

264. De Feo, C.J.; Weiss, C.D. Escape from human immunodeficiency virus type 1 (hiv-1) entry inhibitors. Viruses 2012, 4, 3859-3911.

265. Cheng-Mayer, C.; Quiroga, M.; Tung, J.W.; Dina, D.; Levy, J.A. Viral determinants of human immunodeficiency virus type $1 \mathrm{t}$-cell or macrophage tropism, cytopathogenicity, and cd4 antigen modulation. J. Virol. 1990, 64, 4390-4398.

266. Berger, E.A. Hiv entry and tropism: The chemokine receptor connection. AIDS 1997, 11 Suppl A, S3-S16.

267. Picchio, G.R.; Gulizia, R.J.; Wehrly, K.; Chesebro, B.; Mosier, D.E. The cell tropism of human immunodeficiency virus type 1 determines the kinetics of plasma viremia in scid mice reconstituted with human peripheral blood leukocytes. J. Virol. 1998, 72, 2002-2009.

268. Deng, H.; Liu, R.; Ellmeier, W.; Choe, S.; Unutmaz, D.; Burkhart, M.; di Marzio, P.; Marmon, S.; Sutton, R.E.; Hill, C.M.; et al. Identification of a major co-receptor for primary isolates of hiv-1. Nature 1996, 381, 661-666.

269. Feng, Y.; Broder, C.C.; Kennedy, P.E.; Berger, E.A. Hiv-1 entry cofactor: Functional cdna cloning of a seven-transmembrane, g protein-coupled receptor. Science 1996, 272, 872-877.

270. Dorr, P.; Westby, M.; Dobbs, S.; Griffin, P.; Irvine, B.; Macartney, M.; Mori, J.; Rickett, G.; Smith-Burchnell, C.; Napier, C.; et al. Maraviroc (uk-427,857), a potent, orally bioavailable, and selective small-molecule inhibitor of chemokine receptor ccr5 with broad-spectrum anti-human immunodeficiency virus type 1 activity. Antimicrob. Agents Chemother. 2005, 49, 4721-4732.

271. Dragic, T.; Trkola, A.; Thompson, D.A.; Cormier, E.G.; Kajumo, F.A.; Maxwell, E.; Lin, S.W.; Ying, W.; Smith, S.O.; Sakmar, T.P.; et al. A binding pocket for a small molecule inhibitor of hiv-1 entry within the transmembrane helices of ccr5. Proc. Natl. Acad. Sci. USA 2000, 97, 5639-5644.

272. Roche, M.; Jakobsen, M.R.; Sterjovski, J.; Ellett, A.; Posta, F.; Lee, B.; Jubb, B.; Westby, M.; Lewin, S.R.; Ramsland, P.A.; et al. Hiv-1 escape from the ccr5 antagonist maraviroc associated 
with an altered and less-efficient mechanism of gp120-ccr5 engagement that attenuates macrophage tropism. J. Virol. 2011, 85, 4330-4342.

273. Fatkenheuer, G.; Nelson, M.; Lazzarin, A.; Konourina, I.; Hoepelman, A.I.; Lampiris, H.; Hirschel, B.; Tebas, P.; Raffi, F.; Trottier, B.; et al. Subgroup analyses of maraviroc in previously treated r5 hiv-1 infection. N. Engl. J. Med. 2008, 359, 1442-1455.

274. Gulick, R.M.; Lalezari, J.; Goodrich, J.; Clumeck, N.; DeJesus, E.; Horban, A.; Nadler, J.; Clotet, B.; Karlsson, A.; Wohlfeiler, M.; et al. Maraviroc for previously treated patients with r5 hiv-1 infection. N. Engl. J. Med. 2008, 359, 1429-1441.

275. Moore, J.P.; Kuritzkes, D.R. A piece de resistance: How hiv-1 escapes small molecule ccr5 inhibitors. Curr. Opin. HIV AIDS 2009, 4, 118-124.

276. Pastore, C.; Ramos, A.; Mosier, D.E. Intrinsic obstacles to human immunodeficiency virus type 1 coreceptor switching. J. Virol. 2004, 78, 7565-7574.

277. Pastore, C.; Nedellec, R.; Ramos, A.; Pontow, S.; Ratner, L.; Mosier, D.E. Human immunodeficiency virus type 1 coreceptor switching: V1/v2 gain-of-fitness mutations compensate for v3 loss-of-fitness mutations. J. Virol. 2006, 80, 750-758.

278. Westby, M. Resistance to ccr5 antagonists. Curr. Opin. HIV AIDS 2007, 2, 137-144.

279. Westby, M.; Smith-Burchnell, C.; Mori, J.; Lewis, M.; Mosley, M.; Stockdale, M.; Dorr, P.; Ciaramella, G.; Perros, M. Reduced maximal inhibition in phenotypic susceptibility assays indicates that viral strains resistant to the ccr5 antagonist maraviroc utilize inhibitor-bound receptor for entry. J. Virol. 2007, 81, 2359-2371.

280. Anastassopoulou, C.G.; Ketas, T.J.; Klasse, P.J.; Moore, J.P. Resistance to ccr5 inhibitors caused by sequence changes in the fusion peptide of hiv-1 gp41. Proc. Natl. Acad. Sci. USA 2009, 106, 5318-5323.

281. Yuan, Y.; Maeda, Y.; Terasawa, H.; Monde, K.; Harada, S.; Yusa, K. A combination of polymorphic mutations in v3 loop of hiv-1 gp120 can confer noncompetitive resistance to maraviroc. Virology 2011, 413, 293-299.

282. Berro, R.; Klasse, P.J.; Jakobsen, M.R.; Gorry, P.R.; Moore, J.P.; Sanders, R.W. V3 determinants of hiv-1 escape from the ccr5 inhibitors maraviroc and vicriviroc. Virology 2012, 427, 158-165.

283. Kilby, J.M.; Hopkins, S.; Venetta, T.M.; DiMassimo, B.; Cloud, G.A.; Lee, J.Y.; Alldredge, L.; Hunter, E.; Lambert, D.; Bolognesi, D.; et al. Potent suppression of hiv-1 replication in humans by t-20, a peptide inhibitor of gp41-mediated virus entry. Nat. Med. 1998, 4, 1302-1307.

284. Matthews, T.; Salgo, M.; Greenberg, M.; Chung, J.; DeMasi, R.; Bolognesi, D. Enfuvirtide: The first therapy to inhibit the entry of hiv-1 into host cd4 lymphocytes. Nat. Rev. 2004, 3, 215-225.

285. Rimsky, L.T.; Shugars, D.C.; Matthews, T.J. Determinants of human immunodeficiency virus type 1 resistance to gp41-derived inhibitory peptides. J. Virol. 1998, 72, 986-993.

286. Wei, X.; Decker, J.M.; Liu, H.; Zhang, Z.; Arani, R.B.; Kilby, J.M.; Saag, M.S.; Wu, X.; Shaw, G.M.; Kappes, J.C. Emergence of resistant human immunodeficiency virus type 1 in patients receiving fusion inhibitor (t-20) monotherapy. Antimicrob. Agents Chemother. 2002, 46, 1896-1905.

287. Poveda, E.; Rodes, B.; Toro, C.; Martin-Carbonero, L.; Gonzalez-Lahoz, J.; Soriano, V. Evolution of the gp41 env region in hiv-infected patients receiving t-20, a fusion inhibitor. AIDS 2002, 16, 1959-1961. 
288. Sista, P.R.; Melby, T.; Davison, D.; Jin, L.; Mosier, S.; Mink, M.; Nelson, E.L.; DeMasi, R.; Cammack, N.; Salgo, M.P.; et al. Characterization of determinants of genotypic and phenotypic resistance to enfuvirtide in baseline and on-treatment hiv-1 isolates. AIDS 2004, 18, 1787-1794.

289. Poveda, E.; Rodes, B.; Lebel-Binay, S.; Faudon, J.L.; Jimenez, V.; Soriano, V. Dynamics of enfuvirtide resistance in hiv-infected patients during and after long-term enfuvirtide salvage therapy. J. Clin. Virol. 2005, 34, 295-301.

290. Cabrera, C.; Marfil, S.; Garcia, E.; Martinez-Picado, J.; Bonjoch, A.; Bofill, M.; Moreno, S.; Ribera, E.; Domingo, P.; Clotet, B.; et al. Genetic evolution of gp41 reveals a highly exclusive relationship between codons 36,38 and 43 in gp41 under long-term enfuvirtide-containing salvage regimen. AIDS 2006, 20, 2075-2080.

291. Ray, N.; Harrison, J.E.; Blackburn, L.A.; Martin, J.N.; Deeks, S.G.; Doms, R.W. Clinical resistance to enfuvirtide does not affect susceptibility of human immunodeficiency virus type 1 to other classes of entry inhibitors. J. Virol. 2007, 81, 3240-3250.

292. Xu, L.; Pozniak, A.; Wildfire, A.; Stanfield-Oakley, S.A.; Mosier, S.M.; Ratcliffe, D.; Workman, J.; Joall, A.; Myers, R.; Smit, E.; et al. Emergence and evolution of enfuvirtide resistance following long-term therapy involves heptad repeat 2 mutations within gp41. Antimicrob. Agents Chemother. 2005, 49, 1113-1119.

293. Cilliers, T.; Moore, P.; Coetzer, M.; Morris, L. In vitro generation of hiv type 1 subtype c isolates resistant to enfuvirtide. AIDS Res. Hum. Retrovir. 2005, 21, 776-783.

294. Mink, M.; Mosier, S.M.; Janumpalli, S.; Davison, D.; Jin, L.; Melby, T.; Sista, P.; Erickson, J.; Lambert, D.; Stanfield-Oakley, S.A.; et al. Impact of human immunodeficiency virus type 1 gp41 amino acid substitutions selected during enfuvirtide treatment on gp41 binding and antiviral potency of enfuvirtide in vitro. J. Virol. 2005, 79, 12447-12454.

295. Menzo, S.; Castagna, A.; Monachetti, A.; Hasson, H.; Danise, A.; Carini, E.; Bagnarelli, P.; Lazzarin, A.; Clementi, M. Genotype and phenotype patterns of human immunodeficiency virus type 1 resistance to enfuvirtide during long-term treatment. Antimicrob. Agents Chemother. 2004, 48, 3253-3259.

296. Nameki, D.; Kodama, E.; Ikeuchi, M.; Mabuchi, N.; Otaka, A.; Tamamura, H.; Ohno, M.; Fujii, N.; Matsuoka, M. Mutations conferring resistance to human immunodeficiency virus type 1 fusion inhibitors are restricted by gp41 and rev-responsive element functions. J. Virol. 2005, 79, 764-770.

297. Greenberg, M.L.; Cammack, N. Resistance to enfuvirtide, the first hiv fusion inhibitor. J. Antimicrob. Chemother. 2004, 54, 333-340.

298. Trivedi, V.D.; Cheng, S.F.; Wu, C.W.; Karthikeyan, R.; Chen, C.J.; Chang, D.K. The llsgiv stretch of the n-terminal region of hiv-1 gp41 is critical for binding to a model peptide, $\mathrm{t} 20$. Protein Eng. 2003, 16, 311-317.

299. Lu, J.; Sista, P.; Giguel, F.; Greenberg, M.; Kuritzkes, D.R. Relative replicative fitness of human immunodeficiency virus type 1 mutants resistant to enfuvirtide (t-20). J. Virol. 2004, 78, 4628-4637.

300. Marconi, V.; Bonhoeffer, S.; Paredes, R.; Lu, J.; Hoh, R.; Martin, J.N.; Deeks, S.G.; Kuritzkes, D.R. Viral dynamics and in vivo fitness of hiv-1 in the presence and absence of enfuvirtide. J. Acquir. Immune Defic. Syndr. 2008, 48, 572-576. 
301. Bai, X.; Wilson, K.L.; Seedorff, J.E.; Ahrens, D.; Green, J.; Davison, D.K.; Jin, L.; Stanfield-Oakley, S.A.; Mosier, S.M.; Melby, T.E.; et al. Impact of the enfuvirtide resistance mutation $\mathrm{n} 43 \mathrm{~d}$ and the associated baseline polymorphism e137k on peptide sensitivity and six-helix bundle structure. Biochemistry 2008, 47, 6662-6670.

302. Watabe, T.; Terakawa, Y.; Watanabe, K.; Ohno, H.; Nakano, H.; Nakatsu, T.; Kato, H.; Izumi, K.; Kodama, E.; Matsuoka, M.; et al. X-ray crystallographic study of an hiv-1 fusion inhibitor with the gp41 s138a substitution. J. Mol. Biol. 2009, 392, 657-665.

303. Haleyur Giri Setty, M.K.; Hewlett, I.K. Point of care technologies for hiv. AIDS Res. Treat. 2014, 2014, 497046.

304. Siliciano, J.D.; Siliciano, R.F. Recent trends in hiv-1 drug resistance. Curr. Opin. Virol. 2013, 3, 487-494.

305. Lee, H.H.; Dineva, M.A.; Chua, Y.L.; Ritchie, A.V.; Ushiro-Lumb, I.; Wisniewski, C.A. Simple amplification-based assay: A nucleic acid-based point-of-care platform for hiv-1 testing. J. Infect. Dis. 2010, 201 Suppl 1, S65-72.

306. Jordan, M.R.; Bennett, D.E.; Bertagnolio, S.; Gilks, C.F.; Sutherland, D. World health organization surveys to monitor hiv drug resistance prevention and associated factors in sentinel antiretroviral treatment sites. Antivir. Therapy 2008, 13 Suppl 2, 15-23.

307. Van den Eede, P.; van Wesenbeeck, L.; Verlinden, Y.; Feyaerts, M.; Smits, V.; Verheyen, A.; Vanhooren, L.; Deloof, A.; Villacian, J.; Pattery, T. Hiv-1 genotyping of the protease-reverse transcriptase and integrase genes to detect mutations that confer antiretroviral resistance. Methods Mol. Biol. 2013, 1030, 37-55.

308. Asahchop, E.L.; Wainberg, M.A.; Sloan, R.D.; Tremblay, C.L. Antiviral drug resistance and the need for development of new hiv-1 reverse transcriptase inhibitors. Antimicrob. Agents Chemother. 2012, 56, 5000-5008.

309. Pirrone, V.; Thakkar, N.; Jacobson, J.M.; Wigdahl, B.; Krebs, F.C. Combinatorial approaches to the prevention and treatment of hiv-1 infection. Antimicrob. Agents Chemother. 2011, 55, 18311842.

(C) 2014 by the authors; licensee MDPI, Basel, Switzerland. This article is an open access article distributed under the terms and conditions of the Creative Commons Attribution license (http://creativecommons.org/licenses/by/4.0/). 